\title{
Trends in Monetary Policy Transparency
}

\author{
PETRA M. GERAATS
}

CESIFO WORKING PAPER NO. 2584

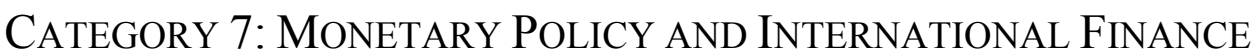

MARCH 2009

\footnotetext{
An electronic version of the paper may be downloaded

- from the SSRN website:

- from the RePEc website: www.SSRN.com

Www.RePEc.org

- from the CESifo website:

www.CESifo-group.org/wp
} 


\title{
Trends in Monetary Policy Transparency
}

\begin{abstract}
Transparency has become a prominent feature of monetary policy. This paper provides an overview of central bank communication practices and is the first to systematically analyze transparency trends throughout the world and across monetary policy frameworks. It shows that increases in information disclosure have not been confined to inflation targeting but extend to other monetary policy frameworks, although there are significant differences. In addition, countries with higher inflation and economic development have undergone larger increases in transparency. Moreover, it shows that greater transparency has been followed by lower average inflation.
\end{abstract}

JEL Code: E42, E58.

Keywords: transparency, monetary policy, central bank communication, monetary policy frameworks.

\author{
Petra Geraats \\ Faculty of Economics \\ University of Cambridge \\ Cambridge, CB3 9DD \\ United Kingdom \\ Petra.Geraats@econ.cam.ac.uk
}

February 2009

I'm grateful to the participants of the Bank of Canada conference "International Experience with the Conduct of Monetary Policy under Inflation Targeting" for their comments, especially my discussants Masayoshi Amamiya, Tomas Holub, Don Kohn and Jan Qvigstad. I thank Umang Rawat for helpful research assistance, and Barry Eichengreen and Nergiz Dincer for sharing their laboriously compiled transparency data set. 


\section{Introduction}

Transparency has become a prominent feature of monetary policy during the last fifteen years, but systematic evidence of transparency trends has been elusive due to a dearth of data. This paper exploits the rich transparency data set collected by Dincer and Eichengreen (2007) to document and analyze trends in monetary policy transparency during the last decade. It investigates not only global trends but also differences across monetary policy frameworks. In addition, it considers the institutional and macroeconomic setting of the transparency trends. Thus, it provides a wide perspective on monetary policy transparency to enhance our understanding.

This paper establishes several stylized facts. First, it shows that there has been a significant increase in the disclosure of information pertinent to monetary policymaking during the last decade. The most pronounced improvement has taken place in the communication of policy decisions and the macroeconomic analysis on which they are based. However, there are significant differences across monetary policy frameworks in this respect. Central banks with inflation targeting have experienced the largest expansion in transparency, while central banks with monetary and exchange rate targeting exhibited the smallest increases in information disclosure, although the rise in transparency during the last decade has been significant for all monetary policy frameworks. Countries with high inflation in the late 1990s and high levels of economic development have undergone the strongest increase in monetary policy transparency. Furthermore, countries with higher monetary policy transparency tend to experience lower subsequent inflation.

Regarding the differences across monetary policy frameworks, inflation targeters tend to have low inflation, a high GDP per capita and the highest levels of transparency. Monetary targeters generally have higher inflation, a low GDP per capita and low levels of transparency. Exchange rate targeters tend to have low inflation, low transparency and a varying degree of economic development. Finally, central banks without an explicit targeting framework have on average an intermediate degree of transparency, with varying levels of inflation and economic development.

This paper contributes to a small but influential empirical literature on transparency practices. Fry, Julius, Mahadeva, Roger and Sterne (2000) were the first to document transparency practices and other features of monetary policymaking throughout the world in a survey of 94 central banks, but only provided a snapshot for 1998. Eijffinger and Geraats (2006) were the first to provide systematic evidence of increases in central bank transparency, but their index was only available for nine major central banks from 1998 to 2002. Dincer and Eichengreen (2007) combined the best of both by compiling the Eijffinger-Geraats index for 100 central banks from 1998 to 2006. While Dincer and Eichengreen (2007) find that transparency has increased throughout the world during the 
last decade, the present paper analyzes in what respects central banks have become more transparent.

Crowe and Meade (2008) also find a rise in transparency but for a smaller sample of 36 countries they obtained by updating the Fry et al. (2000) transparency data for 2003. In addition, they document a significant increase in de jure central bank independence from the 1980 s to 2003 based on a sample of 69 countries. The presence of significant differences in information disclosure across monetary policy frameworks was first established by Geraats (2006), using the Fry et al. (2000) survey data. The present paper updates and extends this analysis using the much richer data set of Dincer and Eichengreen (2007).

There is also interesting survey evidence of central bank's perceptions of the relevance of transparency. The 1998 survey of 94 central banks by Fry et al. (2000) shows that $74 \%$ of central banks consider transparency a 'vital' or 'very important' component of their monetary policy framework. In addition, based on a survey of 88 central bankers, Blinder (2000) finds that transparency is considered a very important factor to establish or maintain credibility, similar to a history of fighting inflation.

The remainder of this paper is organized as follows. Section 2 describes some of the key insights of the theoretical literature on monetary policy transparency. Section 3 reviews two types of transparency measures that have been used in the empirical literature. Global trends in monetary policy transparency are discussed in section 4. Differences across monetary policy frameworks are analyzed in section 5. Section 6 considers the institutional and macroeconomic context of the observed transparency trends. Some recent challenges in monetary policy transparency are discussed in section 7 , and section 8 concludes.

\section{Theoretical Insights}

Monetary policy transparency is typically defined as a situation in which there is no asymmetric information about monetary policymaking (e.g. Geraats 2002). This pertains to all the different facets of policymaking. Geraats (2002) presents a framework that distinguishes five aspects, which has also been adopted for two important transparency measures discussed in section 3. Political transparency refers to clarity about the central bank's objectives, economic transparency about the economic information used for the policy decision, procedural transparency about the decision-making process, policy transparency about the monetary policy stance, and operational transparency about the effects of monetary policy implementation. It is useful to present a stylized monetary policy model to illustrate these aspects and explain the effects of transparency. 
Suppose the central bank maximizes the objective function

$$
W=-\frac{1}{2} \alpha(\pi-\tau)^{2}-\frac{1}{2}(1-\alpha)(y-\kappa)^{2}
$$

where $\pi$ denotes inflation, $y$ the output gap, $\tau$ the central bank's inflation target, $\kappa$ its output gap target, and $\alpha$ the relative weight on inflation stabilization, with $\alpha \in(0,1)$. The economy is described by an expectations-augmented Phillips equation:

$$
\pi=\pi^{e}+y+s
$$

where $\pi^{e}$ denotes private sector inflation expectations, and $s$ is a supply shock. In addition, there is an aggregate demand equation:

$$
y=-r+d
$$

where $r$ denotes the real interest rate, which is the central bank's policy instrument, and $d$ is a demand shock.

In this model, political transparency refers to the central bank's objectives (1), economic transparency to the aggregate demand and supply shocks $d_{a}$ and $s_{a}$ that are anticipated by the central bank when it sets the policy rate, procedural transparency to the central bank's decision procedure (e.g. to optimally set $r$ under discretion), policy transparency to the precise policy stance $r$, and operational transparency to the aggregate demand and supply shocks $d_{u}$ and $s_{u}$ that are unanticipated by the central bank when it sets the policy rate, where $\varepsilon=\varepsilon_{a}+\varepsilon_{u}$ and $\varepsilon_{u}$ is independently distributed with $\mathrm{E}\left[\varepsilon_{u}\right]=0$ for $\varepsilon \in\{s, d\}$.

To understand the effects of transparency, assume that the variables $x \in\{\tau, \kappa, s, d\}$ are stochastic and independently distributed with $\mathrm{E}[x]=0$ and $\operatorname{Var}[x]=\sigma_{x}^{2}>0$. In addition, the private sector rationally forms its inflation expectations $\pi^{e}$ before the central bank optimally sets its policy rate $r$. As an opacity benchmark, consider the case in which $\tau, \kappa, s_{a}$ and $d_{a}$ are only known to the central bank but not to the private sector when it forms its inflation expectations $\pi^{e}$. Then, substituting (2) and (3) into (1) and taking the first order condition with respect to $r$ (given $\pi^{e}$ ), it is straightforward to show that

$$
r=\alpha\left(\pi^{e}-\tau\right)-(1-\alpha) \kappa+\alpha s_{a}+d_{a}
$$

The policy rate $r$ reflects both the central bank's preferences ( $\tau$ and $\kappa)$ and the macroeconomic shocks that it anticipates $\left(d_{a}\right.$ and $\left.s_{a}\right)$. Substituting (4) into (3) and (2) it follows that

$$
\begin{aligned}
& y=\alpha\left(\tau-\pi^{e}-s\right)+(1-\alpha) \kappa+\alpha s_{u}+d_{u} \\
& \pi=\alpha \tau+(1-\alpha)\left(\pi^{e}+\kappa+s\right)+\alpha s_{u}+d_{u}
\end{aligned}
$$


So, the demand shock anticipated by the central bank is completely offset, and the output gap and inflation depend on the central bank's preferences $(\tau$ and $\kappa)$, the supply shock $(s)$ and the unanticipated shocks $\left(d_{u}\right.$ and $\left.s_{u}\right)$.

Now suppose that the central bank publishes its (medium-term) forecasts for inflation and output, which equal $\pi_{c b}=\pi^{e}-r+d_{a}+s_{a}$ and $y_{c b}=-r+d_{a}$. This allows the private sector to identify the macroeconomic shocks anticipated by the central bank ( $d_{a}$ and $s_{a}$ ), so that it can deduce the central bank's policy preferences from the policy rate using (4). ${ }^{1}$ Thus, economic transparency helps the public to infer the central bank's intentions from its policy actions.

Once the outcomes for output and inflation have been realized, they can be used to identify the macroeconomic shocks $d$ and $s$ using (3) and (2). Furthermore, disclosure of the shocks that were not anticipated by the central bank $\left(d_{u}\right.$ and $\left.s_{u}\right)$ allows the private sector to deduce the central bank's policy preferences from output or inflation using (5) or (6). ${ }^{2}$ Thus, operational transparency helps the public to infer the central bank's intentions from macroeconomic outcomes.

In general, transparency can have two types of effects, information and incentive effects (Geraats $(2002,2006)$ ). Information effects are the direct consequences of the removal of information asymmetries, such as a reduction in uncertainty. Incentive effects are the indirect influences that stem from a change in the information structure. For instance, the fact that economic and operational transparency allow the private sector to better infer the central bank's intentions from its policy actions and outcomes gives the central bank a greater incentive to build reputation. Also, the disclosure of public information could have a disproportionate effect when financial markets rely on it to coordinate their actions.

\subsection{Information Effects}

The model above could be used to investigate information effects. ${ }^{3}$ Assume for simplicity that the central bank has perfect information (i.e. $d_{u}=s_{u}=0$ ). Then, substituting (5)

\footnotetext{
${ }^{1}$ This presumes that the private sector knows the structure of the economy, in particular the macroeconomic model used by the central bank for policy analysis. So disclosure of the latter is also important for transparency.

${ }^{2}$ In practice, monetary policy transmission lags are longer for inflation than for output, so inflation could be affected by supply shocks that arise after output has been realized. This means that not only the unanticipated demand shock $d_{u}$ but also the anticipated supply shock $s_{a}$ is needed to deduce the central bank's policy preferences from output (using $y=\alpha\left(\tau-\pi^{e}-s_{a}\right)+(1-\alpha) \kappa+d_{u}$ ), whereas additional information about anticipated shocks is not required to deduce policy preferences from inflation.

${ }^{3}$ The following analysis is similar to the model of Geraats (2007) with perfect common knowledge.
} 
and (6) into (1) yields

$$
W=-\frac{1}{2} \alpha(1-\alpha)\left(\pi^{e}-\tau+\kappa+s\right)^{2}
$$

For the opacity benchmark with asymmetric information about $\tau, \kappa, d$ and $s$, rational expectations imply that $\pi^{e}=\mathrm{E}[\pi]=0$ using (6), so that

$$
\mathrm{E}\left[W_{O}\right]=-\frac{1}{2} \alpha(1-\alpha)\left[\sigma_{\tau}^{2}+\sigma_{\kappa}^{2}+\sigma_{s}^{2}\right]
$$

Now suppose that the central bank discloses its inflation target $\tau$ before the private sector forms its inflation expectations. Then (6) implies $\pi^{e}=\mathrm{E}[\pi \mid \tau]=\tau$. Substituting this into (7) yields

$$
\mathrm{E}\left[W_{\tau}\right]=-\frac{1}{2} \alpha(1-\alpha)\left[\sigma_{\kappa}^{2}+\sigma_{s}^{2}\right]>\mathrm{E}\left[W_{O}\right]
$$

So, the publication of the central bank's inflation target is beneficial. The reason is that the private sector aligns its inflation expectations $\pi^{e}$ with the target $\tau$, which makes it easier for the central bank to reach the inflation target. This provides a powerful argument for publishing an explicit inflation target, which is done by most central banks nowadays.

However, the desirability of transparency about the central bank's preferences does not extend to the output gap target $\kappa$. In that case, rational expectations imply $\pi^{e}=$ $\mathrm{E}[\pi \mid \kappa]=\frac{1-\alpha}{\alpha} \kappa$ using (6), so that (7) yields

$$
\mathrm{E}\left[W_{\kappa}\right]=-\frac{1}{2} \alpha(1-\alpha)\left[\sigma_{\tau}^{2}+\frac{1}{\alpha} \sigma_{\kappa}^{2}+\sigma_{s}^{2}\right]<\mathrm{E}\left[W_{O}\right]
$$

The disclosure of the output gap target $\kappa$ is undesirable because the private sector rationally incorporates it into its expectations. So, a higher output gap target $\kappa$ increases inflation expectations $\pi^{e}$, which leads to a higher interest rate $r$ and depresses the output gap $y$ (see also (5)), thereby making it harder to achieve the target $\kappa$. In addition, the greater volatility of inflation expectations harms inflation stabilization. This argument for opacity about the central bank's output preferences is similar to Cukierman and Meltzer (1986) and helps to explain central banks' reticence about their output preferences.

Turning to transparency of macroeconomic shocks, the publication of demand shocks $d$ has no effect on $\mathrm{E}[W]$, although it would lead to smaller forecast errors for the policy rate. However, the publication of the supply shock $s$ is detrimental in this model. In this case, rational expectations imply $\pi^{e}=\mathrm{E}[\pi \mid s]=\frac{1-\alpha}{\alpha} s$ using (6), so that (7) yields

$$
\mathrm{E}\left[W_{s}\right]=-\frac{1}{2} \alpha(1-\alpha)\left[\sigma_{\tau}^{2}+\sigma_{\kappa}^{2}+\frac{1}{\alpha} \sigma_{s}^{2}\right]<\mathrm{E}\left[W_{O}\right]
$$

Intuitively, a higher supply shock $s$ raises inflation expectations $\pi^{e}$, which makes it harder to stabilize inflation. This drawback of transparency about supply shocks is in line with 
Cukierman (2001), although it does not incorporate beneficial incentive effects discussed below.

Providing information about future policy rates could also have beneficial information effects, since the effectiveness of monetary policy depends on longer term interest rates that are affected by expectations of the policy path (Rudebusch and Williams 2006).

To sum up, information effects of transparency reduce uncertainty, but they are not necessarily beneficial because the private sector incorporates the information disclosures into its expectations, which could cause greater economic volatility.

\subsection{Incentive Effects}

The communication of macroeconomic shocks could also have important incentive effects. As shown above, the disclosure of the demand and supply shocks anticipated by the central bank allows the private sector to infer the central bank's intentions from the policy decision. This gives the central bank a strong incentive to refrain from inflationary policy since it would quickly be detected by the private sector and lead to higher inflation expectations. Opacity about anticipated macroeconomic shocks that are reflected in the policy decision makes the policy rate a noisier signal of the central bank's intentions, so that private sector inflation expectations are less sensitive to it, which gives the central bank less incentive to build reputation. Thus, economic transparency reduces the inflationary bias associated with discretionary monetary policy, as formally shown by Geraats (2005). In fact, it could completely eliminate the inflation bias if the adjustment of inflation expectations is incorporated into the monetary policy transmission mechanism (Geraats 2001). It also gives the central bank greater flexibility to respond to anticipated macroeconomic shocks, whereas under economic opacity the central bank no longer completely offsets anticipated demand shocks to avoid upsetting inflation expectations (Geraats 2000, Walsh 2007).

Similarly, transparency about unanticipated disturbances or control errors makes the policy outcome a more accurate signal of the central bank's intentions. This makes inflation expectations more sensitive to unexpected policy outcomes, which again gives the central bank a greater incentive to build reputation. Thus, operational transparency could also reduce the inflation bias, as shown by Faust and Svensson (2001).

Besides beneficial reputation effects on the central bank, transparency could also alter the incentives of the private sector. In particular, financial markets are likely to put disproportionate weight on public information to coordinate their actions. Although this could enhance the effectiveness of central bank communications, if these information disclosures are noisy relative to the private information of investors, they could induce greater economic volatility, as shown by Morris and Shin (2002). The stronger reliance 
on public communications also reduces the informativeness of market signals (Morris and Shin 2005). In addition, public disclosures could crowd out private sector efforts to acquire information and thereby reduce the net improvement in forecast accuracy (Tong 2005).

This brief overview just highlights some important theoretical insights. A more thorough review of the transparency literature is provided by Geraats (2002). For a more recent non-technical discussion, see Geraats (2006).

\section{Transparency Measures}

One of the biggest impediments to transparency research has been the dearth of data. This is not surprising since it is challenging to measure to what extent the private sector has the same information as monetary policymakers and fully understands the policymaking process. There are two main approaches to measuring transparency.

An influential strand of the literature focuses on financial market reactions to monetary policy decisions and communications (see Blinder, Ehrmann, Fratzscher, Haan and Jansen (2008) for a recent survey). If there is perfect transparency, the absence of asymmetric information makes imminent monetary policy decisions perfectly predictable, so efficient financial markets should not react to monetary policy decisions. On the other hand, financial market reactions to central bank communications could be used to gauge their informativeness.

This approach has the great benefit of allowing very high frequency analysis of the effects of central bank communications, but it is complicated by the fact that monetary policy decisions are often released together with policy explanations. Furthermore, so far the analysis has been limited to a handful of mostly developed countries. Relying on market reactions in developing countries is more problematic since they often suffer from financial market inefficiencies.

The other approach to measuring transparency focuses on the availability of information that is pertinent to monetary policymaking. Fry et al. (2000) provide a valuable dataset in this respect, which is based on a survey of 94 central banks conducted in 1998. Eijffinger and Geraats (2006) present an index of transparency that distinguishes five aspects, following Geraats (2002). They compiled it for nine major central banks from 1998 to 2002, which reveals a pronounced rise in transparency. Dincer and Eichengreen (2007) adopt the Eijffinger-Geraats index and compiled it for 100 central banks from 1998 to 2006, providing the most comprehensive transparency data set to date. ${ }^{4}$ Crowe

\footnotetext{
${ }^{4}$ The Eijffinger-Geraats index has 15 items, but its scoring allows for the identification of 24 information disclosure practices, so the Dincer and Eichengreen (2007) data set effectively yields a total of $24 * 100 * 9=$ 21,600 data points!
} 
Figure 1: Trend in monetary policy transparency

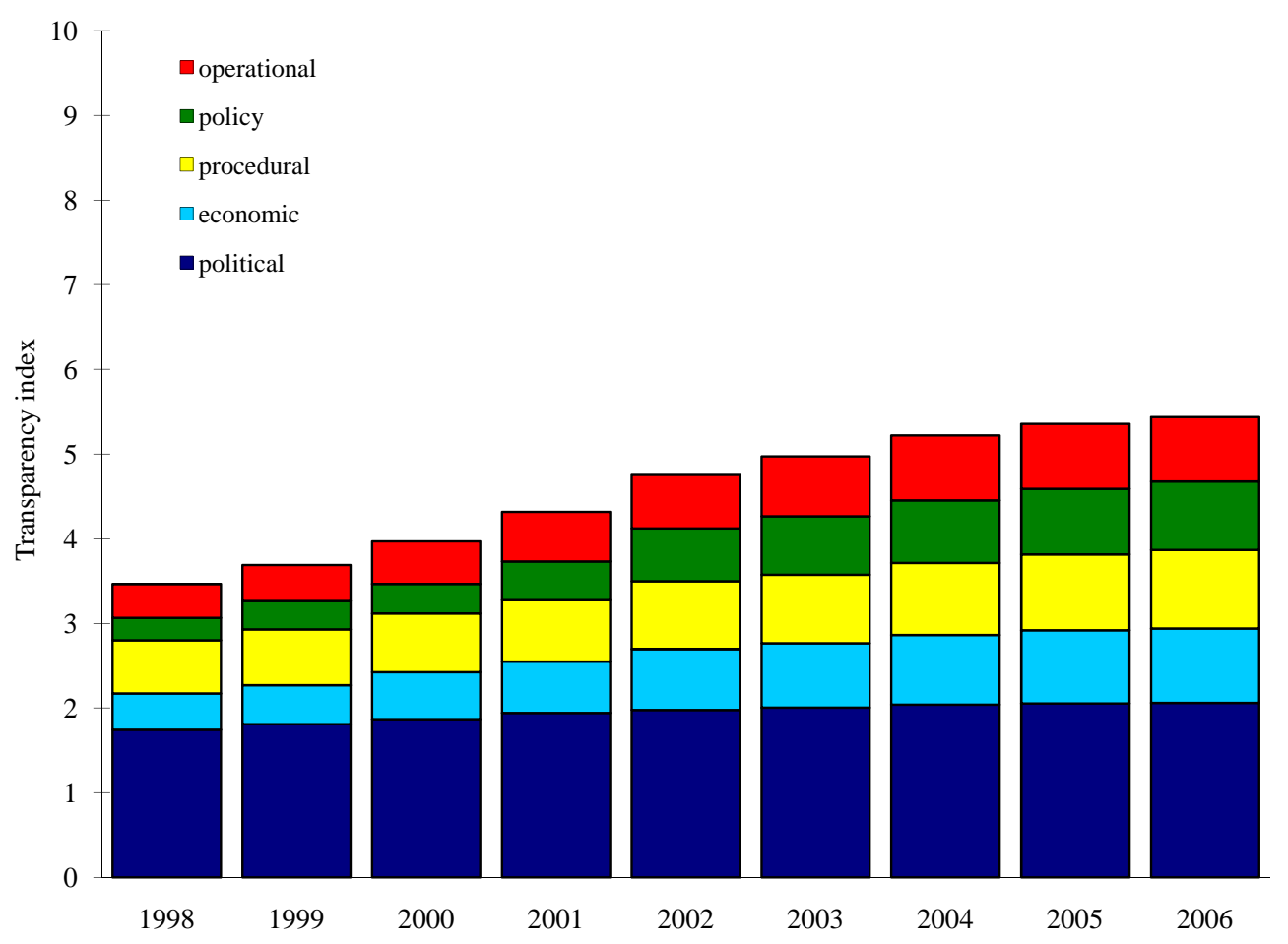

Note: Average of Eijffinger-Geraats transparency index over 98 observations. Source: Dincer and Eichengreen (2007) data set.

and Meade (2008) propose an alternative transparency index that also distinguishes five aspects like Geraats (2002), but they use the Fry et al. (2000) survey from 1998 and used public information to update it for 40 central banks in 2003. Their index is useful since it captures several issues differently compared to the Eijffinger-Geraats index. However, it is available for a more limited sample of central banks and for only two years. In addition, the different ways in which the transparency data for 1998 and 2003 was collected makes the change in their index a noisier measure of transparency trends. As a result, the analysis in the present paper relies on the transparency data collected by Dincer and Eichengreen (2007).

\section{Transparency Trends}

There has been a remarkable increase in monetary policy transparency during the last decade. Figure 1 shows the average of the Eijffinger-Geraats transparency index across 98 central banks from 1998 to 2006, using the data set compiled by Dincer and Eichengreen 
Table 1: Trends in monetary policy transparency

\begin{tabular}{lrrc} 
& 1998 & 2006 & Change (in percent point) \\
\hline Transparency average & 3.46 & 5.45 & $13.2 \%$ \\
- Political & 1.74 & 2.06 & $10.5 \%$ \\
- Economic & 0.43 & 0.88 & $15.0 \%$ \\
- Procedural & 0.63 & 0.93 & $10.0 \%$ \\
- Policy & 0.27 & 0.81 & $18.2 \%$ \\
- Operational & 0.40 & 0.76 & $12.1 \%$ \\
\hline
\end{tabular}

Note: Unweighted average of the Eijffinger-Geraats transparency index across 98 central banks. The index has a maximum of 15 and 3 for the overall index and each of its five components, respectively. Source: Dincer and Eichengreen (2007) data set.

(2007). ${ }^{5}$ The figure shows a clear upward trend in the degree of information disclosure about monetary policy. This also holds for each of the five components of the transparency index. Dincer and Eichengreen (2007) show that the rise in transparency has not been confined to a small group of advanced countries. Although they find that transparency has been much higher in the developed world, the average transparency index (weighted by the level of economic development) has increased substantially for both developed, emerging and developing countries. The rise in transparency also extends across monetary policy frameworks, as is shown in section 5 .

Table 1 shows the average transparency index for 1998 and 2006. The average of the overall index has risen from 3.46 in 1998 to 5.45 in 2006 out of a maximum of 15, which corresponds to an increase of 13.2 percent point. The average scores for the five transparency aspects (which have a maximum of 3) have also each risen by at least 10 percent point, with the largest gains in policy and economic transparency. The increases in transparency are all statistically significant; a paired t-test yields a p-value of less than 0.001 for the overall index and each of its five components. So, on average there has been a highly significant rise in monetary policy transparency for all five aspects. ${ }^{6}$

To investigate more specifically how central banks have become more transparent, the scores for the 15 items of the Eijffinger-Geraats transparency index are used to deduce whether a particular type of information is disclosed. Thus, the quantitative EijffingerGeraats index is inverted to obtain qualitative information about central bank disclosure practices.

\footnotetext{
${ }^{5}$ The sample of countries is listed in the data appendix.

${ }^{6}$ This is in contrast to Crowe and Meade (2008), who could only detect a significant increase in economic and policy transparency from 1998 to 2003 using their index and sample of 40 central banks.
} 
Table 2: Trends in information disclosure

\begin{tabular}{lrrc}
\hline Information disclosure & 1998 & 2006 & Change \\
\hline Political transparency & & & \\
- Monetary policy objectives & 90 & 93 & 3 \\
$\quad$ with prioritization & 38 & 46 & $8^{*}$ \\
- Quantification primary objective & 43 & 62 & $19^{* * *}$ \\
- Explicit instrument independence & 36 & 48 & $12^{* *}$ \\
Economic transparency & & & \\
- Numerical macroeconomic forecasts & 18 & 56 & $38^{* * *}$ \\
$\quad$ quarterly, medium term for inflation and output & 4 & 17 & $13^{* * *}$ \\
- Macroeconomic policy model & 6 & 19 & $13^{* * *}$ \\
Procedural transparency & & & \\
- Monetary policy strategy & 51 & 67 & $16^{* *}$ \\
- Minutes & 6 & 16 & $10^{* * *}$ \\
- Voting records & 5 & 10 & $5^{* *}$ \\
Policy transparency & & & \\
- Policy adjustment & 17 & 53 & $36^{* * *}$ \\
- Policy explanation & 14 & 43 & $29^{* * *}$ \\
- Policy inclination & 0 & 3 & $3^{* *}$ \\
Operational transparency & & & \\
- Control errors operating target & 10 & 24 & $14^{* * *}$ \\
- Transmission disturbances & 20 & 46 & $26^{* * *}$ \\
- Evaluation monetary policy outcomes & 38 & 63 & $25^{* * *}$ \\
Observations & 98 & \\
\hline
\end{tabular}

Note: Asterisks indicate change from 1998 to 2006 is significant at ${ }^{*} 10 \%,{ }^{* *} 5 \%$ or ${ }^{* * *} 1 \%$.

Source: Dincer and Eichengreen (2007) data set.

Table 2 shows whether central banks disclosed various types of information relevant to monetary policymaking in 1998 and 2006, structured by transparency aspect. Regarding political transparency, a formal statement of monetary policy objectives is nearly universal, with the number of central banks increasing slightly to 93 (out of 98) in 2006. Generally, there are multiple monetary policy objectives that could be conflicting, but less than half of central banks identify a primary objective or provide an explicit prioritization, although the number increased modestly to 46 in 2006. The formal monetary policy objectives are often fuzzy, but a large majority of central banks (62 out of 98) nowadays present a quantification of their primary objective(s), which constitutes a major increase compared to 1998. Most prominently, this takes the form of a long-term inflation tar- 
get. More generally, the use of explicit targets or monitoring ranges for the exchange rate, monetary aggregates or inflation already experienced a dramatic increase during the 1990s (Fry et al. 2000). Such numeric targets provide useful nominal anchors for private sector expectations and performance criteria for central bank accountability.

Another issue that contributes to political transparency is the presence of explicit instrument independence or a central bank contract (possibly subject to an explicit override procedure). The number of central banks that enjoy such protection from political pressures has increased steadily during the last decade to nearly a majority of the sample. However, this probably underestimates the prevalence of instrument independence because financial markets may provide an effective deterrent to undue political interference with monetary policy. Indeed, in the survey by Fry et al. (2000) a large majority of central banks reported to enjoy independence without significant qualifications.

Turning to economic transparency, the publication of forecasts or other forwardlooking analysis was already common in 1998 (Fry et al. 2000), but these forward-looking assessments were often entirely qualitative in nature. This has changed remarkably during the last decade. The number of central banks that releases numerical central bank forecasts for inflation or output has jumped from 18 to 56 in 2006. For the purpose of economic transparency, it is important that these macroeconomic forecasts are for both inflation and output, span the horizon of monetary policy transmission (typically one to two years), and are published at least quarterly to reflect the latest macroeconomic data releases. The reason is that this allows the private sector to better understand the central bank's monetary policy actions and infer its intentions, as explained in section 2. But in this respect, transparency is more limited and only 17 out of 98 central banks published their quantitative medium term forecasts for inflation and output every quarter in 2006, although this constitutes a significant increase compared to 1998. The disclosure of the central bank's macroeconometric model for policy analysis and forecasting has experienced a similar rise from 6 to 19 in 2006. Overall, there has been a sea change in economic transparency during the last decade with a much greater focus now on quantitative analysis.

Concerning procedural transparency, the release of an explicit monetary policy strategy has gained further ground with an increase from about one-half to two-thirds of central banks. The strategy describes conceptually how the monetary policy instrument is adjusted in response to economic information to reach the policy objectives. For instance, for inflation targeting this typically involves adjusting the policy rate so that the medium term forecast for inflation is in line with the inflation target. Thus, inflation targeting essentially uses the medium-term inflation forecast like an intermediate target, implying inflation-forecast targeting (Svensson 1997). Most monetary policy strategies, with the exception of strict exchange rate targeting, leave much scope for discretion, which gives 
an important role to minutes and voting records to shed light on the decision-making process.

There has been a significant increase in the publication of minutes (or other comprehensive accounts of the monetary policy deliberations) within eight weeks, from 6 central banks in 1998 to 16 in 2006. The minutes are generally non-verbatim and unattributed, with the exception of reservations against the policy decision raised by dissenters, although the Swedish Riksbank has recently introduced attributed minutes. ${ }^{7}$ The number of central banks that release voting records within eight weeks has doubled but remains low with a frequency of only 10 . These could be non-attributed voting patterns or individual voting records, but the latter are only released by 5 central banks (in Hungary, Japan, Sweden, United Kingdom and United States). All in all, transparency about policy deliberations remains quite scarce.

Moving on to policy transparency, a majority of central banks nowadays promptly announce decisions to adjust the main policy operating instrument or target, and most of them also provide an explanation, which appears to be a big change compared to $1998 .^{8}$ An important feature of monetary policymaking is that the policy instrument is generally adjusted in discrete steps, so central bankers often decide not to make a policy adjustment. But few provide adequate explanations for all policy decisions, including when there is no change. ${ }^{9}$ This limits transparency, since decisions not to adjust policy settings are also important and explanations of them could help the private sector to better understand monetary policymaking.

Since the policy instrument is adjusted in discrete steps (typically 25 basis points for policy rates), it provides an imprecise indicator of the policy stance. For instance, central bankers may decide to set a policy rate of $4 \%$ while their desired rate would be $4.1 \%$. Clearly, it would contribute to transparency to communicate this policy inclination. Furthermore, since monetary policy transmission depends on expectations of future policy, the optimal decision actually involves a path for the policy instrument. But transparency about a policy inclination or projected policy path is very rare; in 2006 it only occurred in New Zealand, Sweden and the United States. Nevertheless, this issue has received a recent impetus as more central banks have started publishing their policy rate projections,

\footnotetext{
${ }^{7}$ The disclosure of verbatim transcripts of policy deliberations is considered undesirable as it could stifle a frank discussion and make monetary policymakers more reluctant to express dissenting opinions, for instance due to career considerations (Meade and Stasavage 2004).

${ }^{8}$ Fry et al. (2000) found greater policy transparency in their 1998 survey, with 76 (out of 94) central banks claiming to provide a prompt explanation of policy changes.

${ }^{9}$ According to the Dincer and Eichengreen (2007) data for 2006, only 4 countries always provide prompt explanations of their monetary policy decisions, Canada, New Zealand, Norway and Switzerland, while Eijffinger and Geraats (2006) also include the European Central Bank, Swedish Riksbank and US Federal Reserve in this respect.
} 
including the Czech Republic, Iceland, New Zealand, Norway and Sweden.

Regarding operational transparency, the number of central banks that regularly evaluate control errors in achieving their operating targets has increased significantly to about a quarter. Central banks have also become much more forthcoming about unanticipated macroeconomic disturbances that affect the monetary policy transmission process, in particular through regular short-term forecasts or analysis of macroeconomic developments, which are released by about half of central banks. Yet few have the frankness to review their past forecast errors, which would reveal unanticipated shocks. ${ }^{10}$

There has also been a large increase in the release of a regular evaluation of monetary policy outcomes, to about two-thirds of central banks. But only one of them (Sweden) actually conducts a rigorous analysis that explicitly accounts for the contribution of monetary policy in achieving its objectives. So, although few central banks receive full scores according to the exacting standards of the Eijffinger-Geraats index, many have made progress towards greater operational transparency.

All in all, table 2 reveals a significant increase during the last decade in the disclosure of a broad range of information that is pertinent to understanding monetary policy. The next section examines whether this trend has been widespread or just confined to central banks with a specific monetary policy framework.

\section{Transparency Across Monetary Policy Frameworks}

The phenomenon of monetary policy transparency is often associated with inflation targeting. Indeed, the most transparent central banks in the Dincer and Eichengreen (2007) sample have been New Zealand, Sweden, the United Kingdom, Canada and the Czech Republic, which are all prominent inflation targeters. However, the rise of transparency also extends to other monetary policy frameworks. This is illustrated in figure 2, which shows the Eijffinger-Geraats index for the Dincer and Eichengreen (2007) data from 1998 to 2006 by monetary policy framework. ${ }^{11}$ The latter is based on the IMF classification of central banks into 'exchange rate targeting', 'monetary targeting', 'inflation targeting' and 'other', as of July 2006. For instance, mainland China and Hong Kong are listed as exchange rate targeters, Argentina and Indonesia as monetary targeters, Canada and the United Kingdom as inflation targeters, while the 'other' category includes the Euro area, India, Japan, Russia and the United States, among others. The classification for the final year of the sample (2006) is used to capture the transparency trends associated with the monetary policy framework, whether through the (gradual) adoption or continuation of it.

\footnotetext{
${ }^{10}$ According to the Dincer and Eichengreen (2007) data, only 2 central banks did so in 2006, Indonesia and Sweden, while Eijffinger and Geraats (2006) also include the Bank of England.

${ }^{11}$ The sample excludes Bermuda and Cuba, for which the monetary policy framework is not available.
} 
Figure 2: Transparency trends across monetary policy frameworks

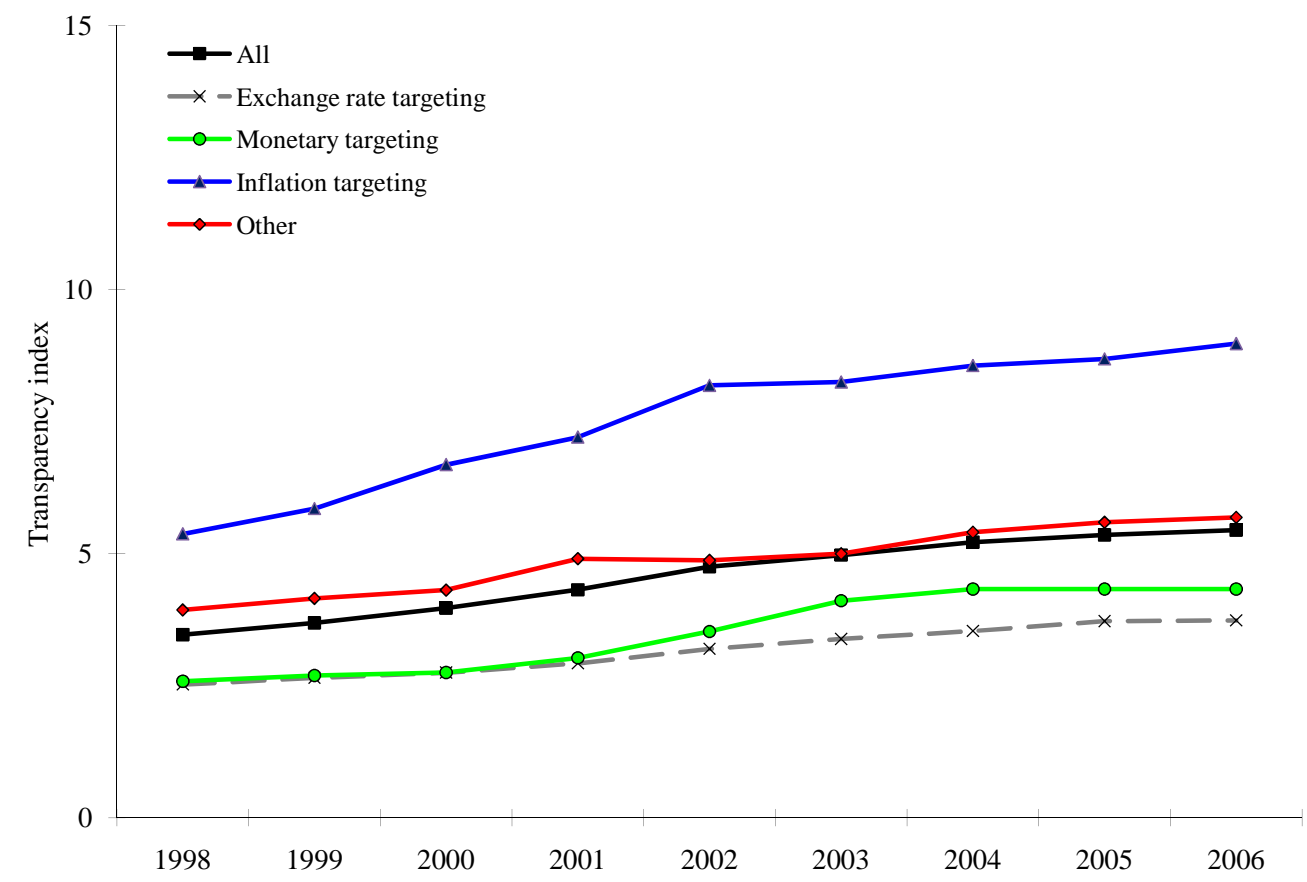

Note: Average over 98 observations. Source: See data appendix.

Figure 2 shows that inflation targeters have on average been the most transparent, followed by central banks without a targeting framework, while monetary and exchange rate targeters are the least transparent. Inflation targeting has also generated the strongest average increase in transparency, in particular from 1998 to 2002. Part of this is driven by the adoption of inflation targeting in a number of countries, including Poland, Thailand, Hungary, Turkey and the Philippines, which are in fact the countries in the sample with the largest rises in the transparency index. But many inflation targeters continue to enhance their disclosure practices over time. Even established inflation targeters, like New Zealand and the United Kingdom, further increased their transparency scores during 1998-2006.

Although the Eijffinger-Geraats index focuses on information that is in general pertinent to understanding monetary policymaking in all respects, it is natural to expect differences in the degree of information disclosure across monetary policy frameworks. In particular, central banks with exchange rate targeting have limited scope (if any) for independent monetary policy in the presence of international capital mobility, so they probably feel far less need to explain their monetary policy actions. Central banks with monetary targeting generally enjoy greater flexibility and face the problem that monetary aggregates can only be controlled imperfectly, which may make them more inclined to focus on operational transparency. Inflation targeting poses a further challenge since the target 
Table 3: Transparency trends across monetary policy frameworks

\begin{tabular}{lcccc} 
Transparency average & Observations & 1998 & 2006 & Change (in percent point) \\
\hline Full sample & 98 & 3.46 & 5.45 & $13.2 \%$ \\
- Exchange rate targeting & 40 & 2.53 & 3.74 & $8.1 \%$ \\
- Monetary targeting & 18 & 2.58 & 4.33 & $11.7 \%$ \\
- Inflation targeting & 24 & 5.38 & 8.98 & $24.0 \%$ \\
- Other & 16 & 3.94 & 5.69 & $11.7 \%$ \\
\hline
\end{tabular}

Note: Unweighted average across central banks of the Eijffinger-Geraats transparency index, which ranges from 0 to 15 . Monetary policy frameworks based on July 2006 IMF classification. Sources: See data appendix.

can only be controlled imperfectly after a long and variable lag of typically about two years. This makes the communication of anticipated macroeconomic developments critical to understanding monetary policy actions, so that economic transparency becomes more relevant.

Despite these differences, it is striking that central banks across all monetary policy frameworks have become more transparent during the last decade. The magnitude of this trend is highlighted in table 3, which shows the average scores of the Eijffinger-Geraats transparency index for 1998 and 2006 by monetary policy framework. The average increase in transparency has been around 10 percent point, except for inflation targeting, which has been responsible for a average rise in transparency of 24 percent point. The increases in transparency in table 3 are all statistically significant; a paired t-test yields a p-value of less than 0.001 for each of the four monetary policy frameworks. So, on average there has been a highly significant rise in transparency across monetary policy frameworks.

Note that table 3 and figure 2 show the average transparency level over time based on the monetary policy framework in 2006. So, the increase is not due to changes in composition (e.g. below average 'others' becoming above average exchange rate targeters, raising the mean in both groups). It appears that exchange rate targeting is by far the most popular framework, but this is probably due to the large number of (very) small open economies in the Dincer and Eichengreen (2007) sample.

To investigate which aspects of transparency have contributed to the rise during the last decade, figures 3, 4, 5 and 6 show the decomposition of the Eijffinger-Geraats index from 1998 to 2006 for exchange rate targeting, monetary targeting, inflation targeting and other frameworks, respectively. To enhance comparability, the figures for the different monetary policy frameworks use the same scale.

Exchange rate targeters have had the lowest average transparency scores, but raised 
Figure 3: Transparency trend for exchange rate targeters

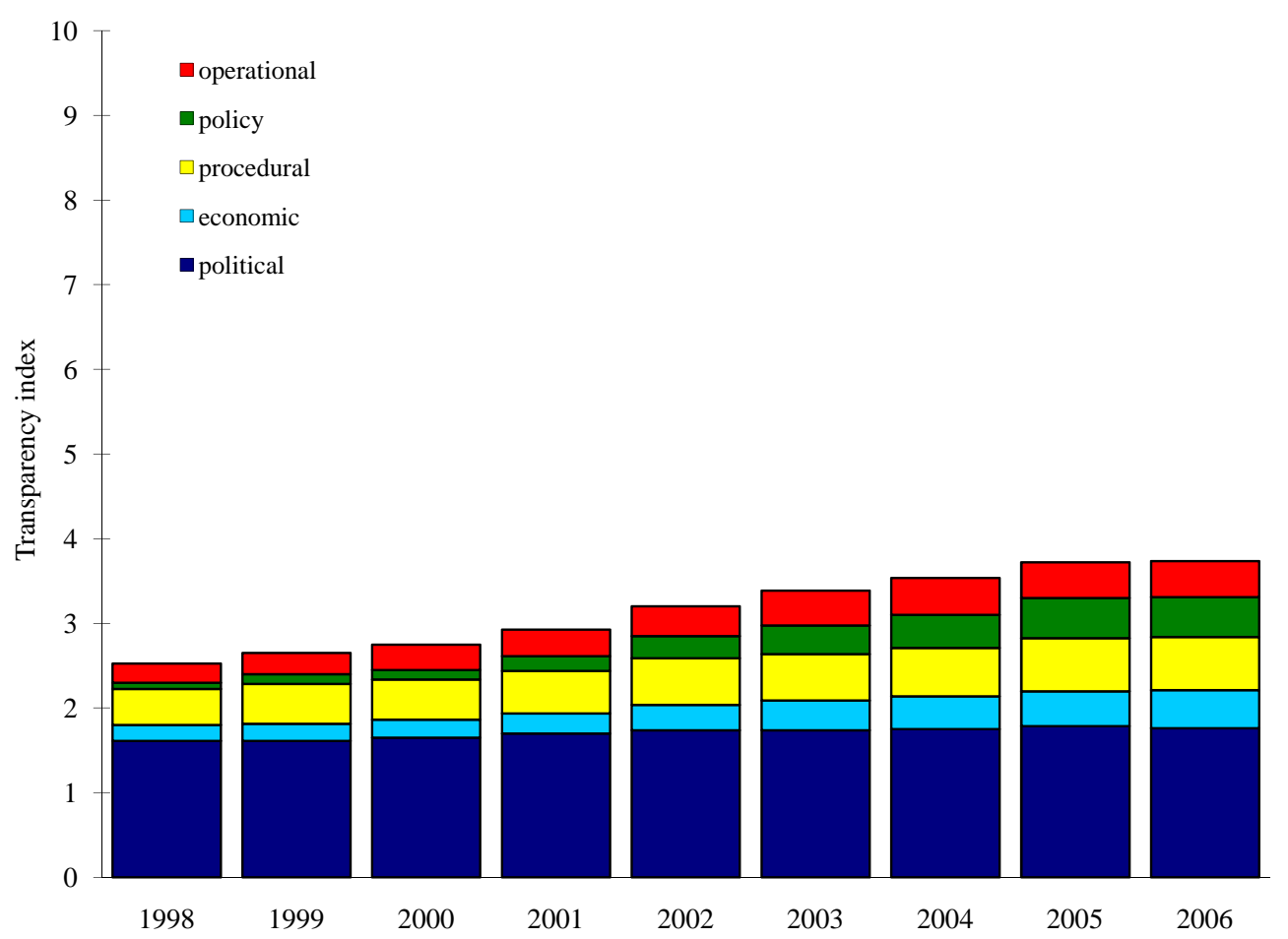

Note: Average of Eijffinger-Geraats transparency index over 40 central banks categorized as exchange rate targeters as of July 2006. Sources: See data appendix.

them in all five aspects. The largest increase occurred for policy transparency, although it remained below average.

Monetary targeters experienced most of their increases in policy and operational transparency. Their gain in operational transparency has been above average, which could help managing the notorious problems associated with the control of monetary aggregates. Nevertheless, they remained below the sample average in every respect except for political transparency.

Inflation targeters have undergone big improvements in all aspects, but foremost in economic and policy transparency. The strong emphasis on the former reflects the inherently forward-looking nature of inflation targeting that is centered around inflation forecasts.

Central banks without a targeting framework, which include some of the world's largest economies, have also seen their strongest increases in economic transparency. Their levels of operational, economic and policy transparency are above the sample average. Although the predilection for greater economic transparency is harder to understand for this category, many central banks without a targeting framework essentially set a policy rate to stabilize medium term fluctuations in output growth and inflation. This makes 
Figure 4: Transparency trend for monetary targeters

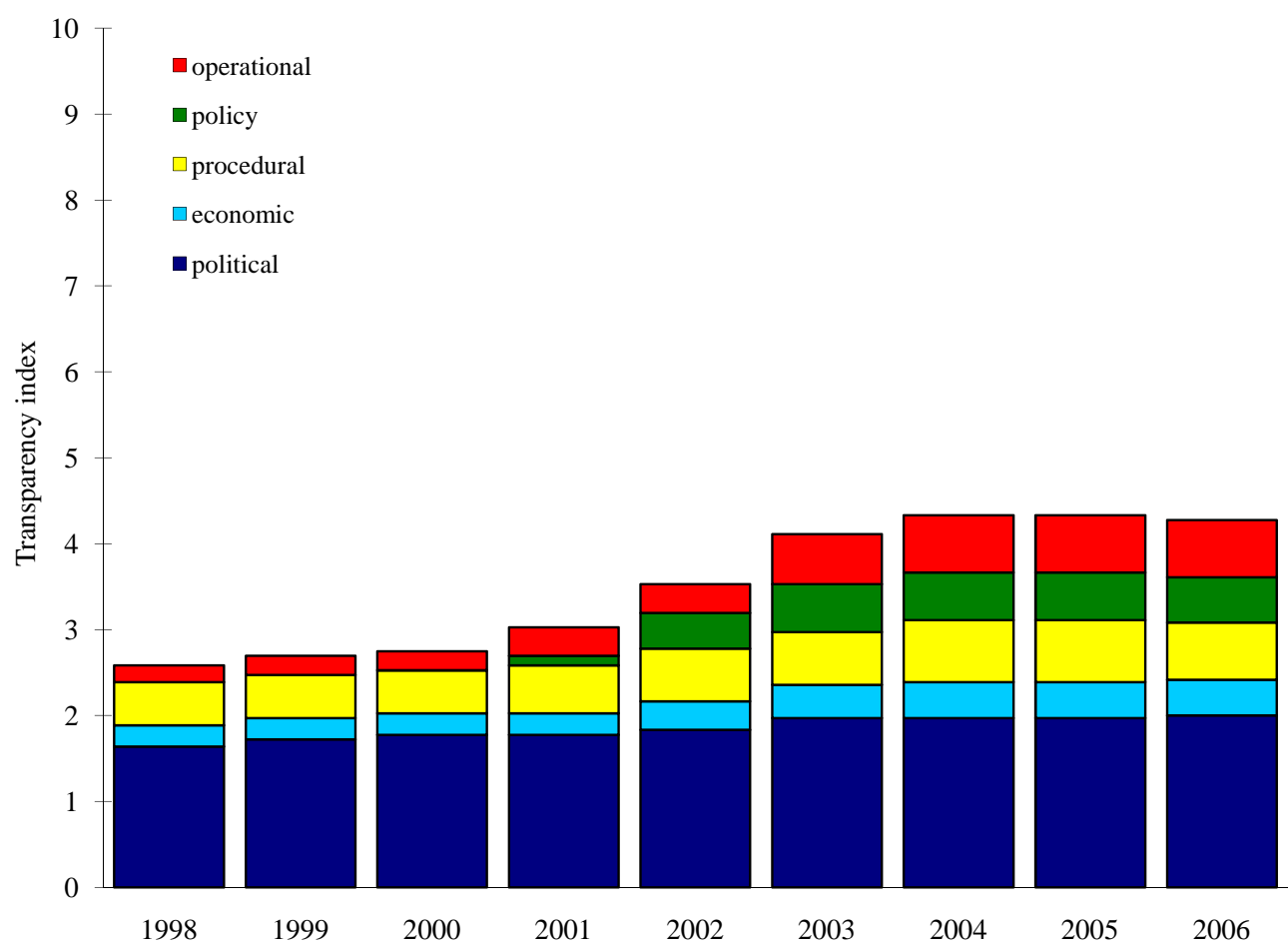

Note: Average of Eijffinger-Geraats transparency index over 18 central banks categorized as monetary targeters as of July 2006. Sources: See data appendix.

their policymaking quite similar to inflation targeting, though without the explicit inflation target and strategy.

All in all, it is clear that there have been substantial increases in transparency across components for all monetary policy frameworks. To analyze more specifically how the degree of transparency differs across frameworks, the Eijffinger-Geraats index is inverted to obtain information about disclosure practices, which is shown in table 7 (included at the end of this paper) for 2006.

Regarding political transparency, a formal statement of monetary objectives is close to universal across monetary policy frameworks, but an explicit prioritization is much more common among inflation targeters, in particular price stability as primary objective. The same holds for a quantification of the primary objective. In fact, all central banks with inflation targeting have a numeric target for inflation, its most characteristic feature. The inflation target often takes the form of a point with a tolerance range of about two percentage points. Central banks without a targeting framework are quite naturally the least likely to have a quantified primary objective. The presence of explicit instrument independence is again most likely for inflation targeters but not so common for exchange rate targeters. The latter is understandable since the lack of discretion makes instrument 
Figure 5: Transparency trend for inflation targeters

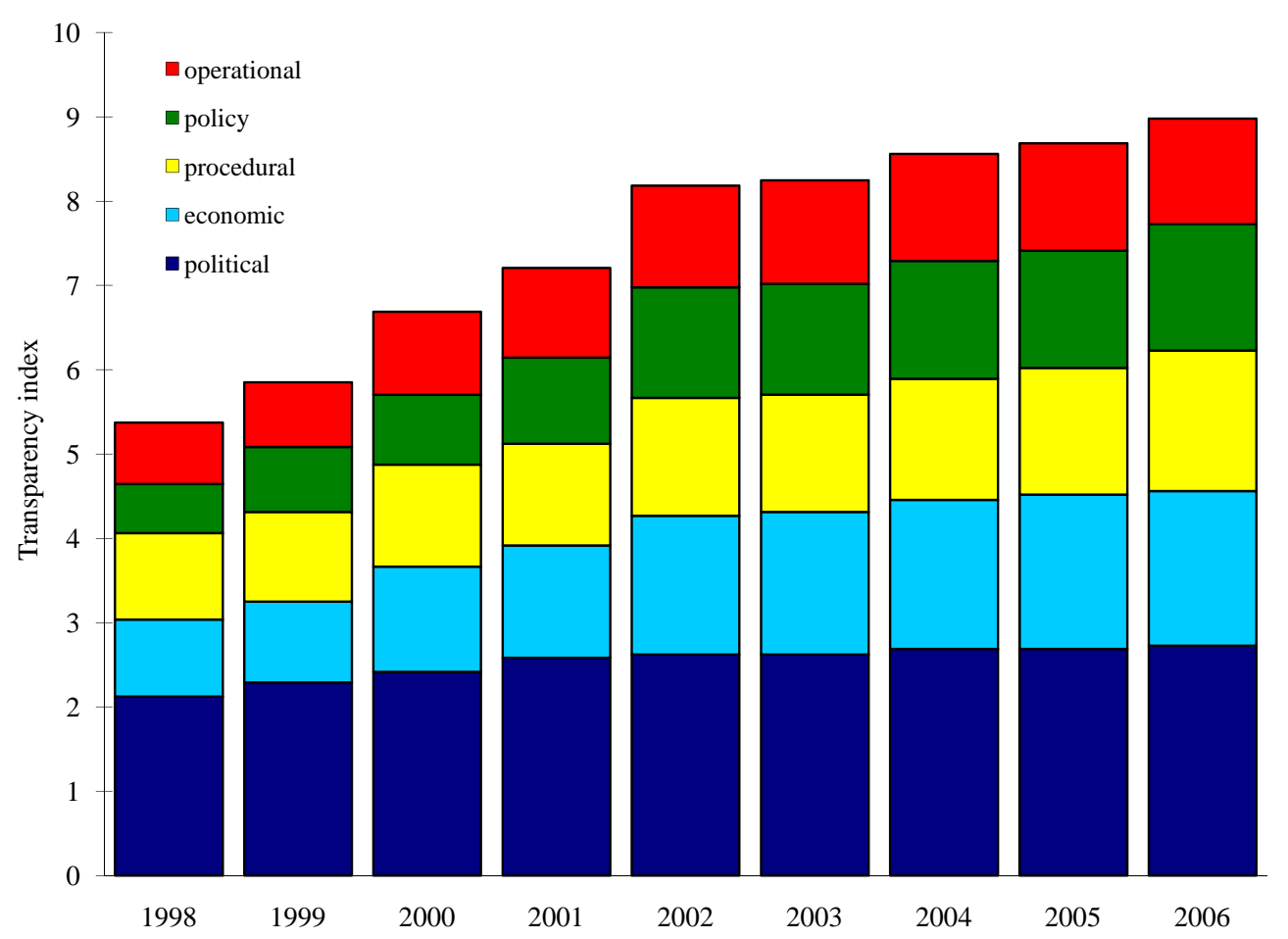

Note: Average of Eijffinger-Geraats transparency index over 24 central banks categorized as inflation targeters as of July 2006. Sources: See data appendix.

independence less relevant.

Moving to economic transparency, nearly all inflation targeters and a large majority of central banks with non-targeting frameworks publish quantitative central bank forecasts for inflation or output, whereas this practice is considerably less common among exchange rate and monetary targeters. Furthermore, about half of inflation targeters release their medium-term forecasts for inflation and output every quarter, and publish the central bank's macroeconomic policy model. Since inflation forecasts play a pivotal role in inflation targeting, the central bank's macroeconomic forecasts are often a focal point of the central bank's communication policy, presented in colorful fan charts that illustrate the underlying uncertainty and balance of risks.

Turning to procedural transparency, all inflation targeters provide an explicit monetary policy strategy, often explained pedagogically in the form of a rule of thumb - to adjust the policy rate when the medium term inflation forecast deviates from the inflation target, essentially capturing inflation-forecast targeting. But an explicit monetary policy strategy is only available for a small majority of other central banks. The minutes and voting records of the monetary policy meetings are published by about $40 \%$ and $30 \%$ of inflation targeters, respectively, whereas this practice is rare among exchange rate and monetary 
Figure 6: Transparency trend for other monetary policy frameworks

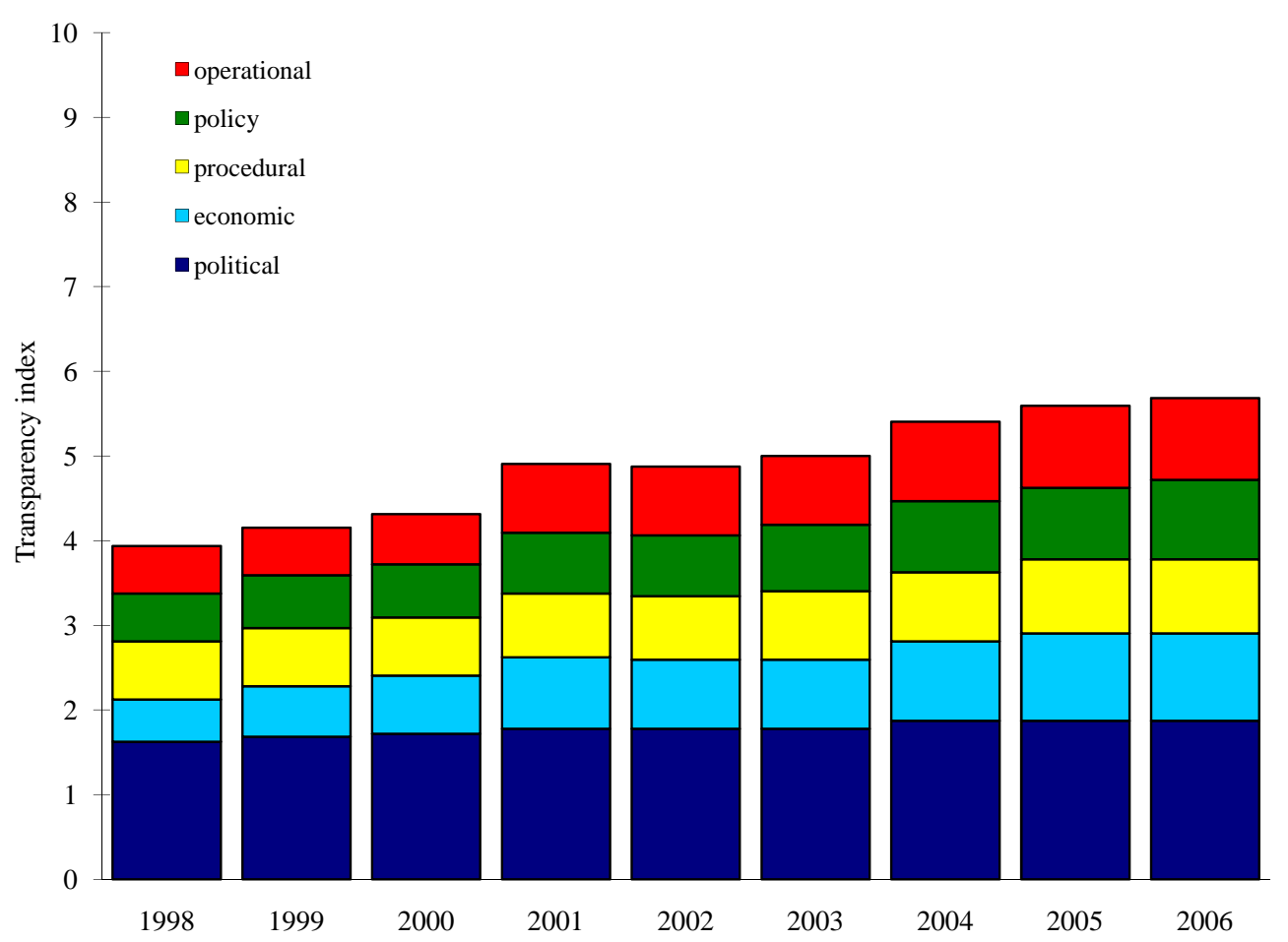

Note: Average of Eijffinger-Geraats transparency index over 16 central banks categorized as having no targeting framework as of July 2006. Sources: See data appendix.

targeters. Thus, inflation targeting distinguishes itself in its much greater focus on the communication of policy deliberations.

Concerning policy transparency, inflation targeters generally promptly announce any policy adjustment and a policy explanation, but this is not so common for exchange rate and monetary targeters. The publication of a policy inclination or projected policy path is done by a few inflation targeters, but is otherwise really rare. In this respect, even inflation targeters tend to remain quite opaque.

Finally, with respect to operational transparency, openness about control errors is provided by about $40 \%$ of inflation targeters and non-targeting central banks, while it is quite unusual for exchange rate targeters. Information about unanticipated transmission disturbances is conveyed by nearly three-quarters of inflation targeters, but by less than a third of exchange rate targeters. An evaluation of monetary policy outcomes is performed by a very large majority of inflation targeting and non-targeting central banks, but only one half of exchange rate and monetary targeters.

All in all, table 7 shows that inflation targeters generally disclose much more information about monetary policymaking than central banks with other monetary policy frameworks, whereas exchange rate and monetary targeters tend to provide consistently 
Table 4: Correlations between central bank transparency and independence Correlation

De jure central bank independence

\begin{tabular}{llllll} 
& Overall & Governor & Policy & Objectives & Limits on lending \\
\hline Transparency & 0.096 & $0.217^{*}$ & 0.066 & 0.175 & 0.003 \\
- Political & $0.397^{* * *}$ & $0.483^{* * *}$ & $0.364^{* * *}$ & $0.342^{* * *}$ & $0.229^{*}$ \\
- Economic & -0.082 & -0.011 & -0.039 & 0.011 & -0.104 \\
- Procedural & 0.003 & $0.212^{*}$ & -0.023 & 0.079 & -0.070 \\
- Policy & -0.002 & -0.014 & 0.018 & 0.067 & -0.033 \\
- Operational & 0.146 & $0.275^{* *}$ & -0.014 & $0.257^{* *}$ & 0.052 \\
\hline
\end{tabular}

Note: Pearson correlation coefficients between the Eijffinger-Geraats transparency index and the Cukierman-Webb-Neyapti index of de jure central bank independence. Asterisks indicate correlation is significant at ${ }^{*} 10 \%,{ }^{* *} 5 \%$ or ${ }^{* * *} 1 \%$. Sample: 68 central banks in 2003 . Sources: See data appendix.

less information. A $\chi^{2}$ test of homogeneity reveals that for nearly all the items, the differences across the four monetary policy frameworks are highly significant. As a result, the monetary policy framework appears to be an important determinant of the degree of information disclosure. This is consistent with the finding by Geraats (2006) based on data from the Fry et al. (2000) survey, but the Dincer and Eichengreen (2007) data set exploited here affords a more comprehensive and up-to-date test, which turns out to produce more consistent and stronger results.

\section{Institutional and Macroeconomic Environment}

It could be argued that the trend in central bank transparency merely mirrors the movement towards greater central bank independence. In particular, to avoid a democratic deficit, independent central banks are often subject to accountability requirements, which necessitates some degree of transparency. Crowe and Meade (2008) show that there has been a significant increase in central bank independence from the 1980s to 2003 for both advanced economies and emerging markets, using the index of de jure central bank independence by Cukierman, Webb and Neyapti (1992) for a sample of 69 central banks. They find that the rise in central bank independence is significantly positively related to the initial level of inflation and democracy, and negatively to the flexibility of the initial de facto exchange rate regime.

Table 4 shows that there is a small positive correlation of 0.096 between de jure central bank independence and central bank transparency in a sample of 68 central banks, using the Cukierman-Webb-Neyapti index that Crowe and Meade (2008) compiled for 
2003 and the Eijffinger-Geraats index compiled by Dincer and Eichengreen (2007) for 2003. Only political transparency is significantly positively related to the overall index of central bank independence with a correlation of 0.397 (p-value 0.001). This is not surprising since there is some overlap between the index for political transparency and central bank independence, which both concern formal monetary policy objectives and operational independence. In fact, there is a significantly positive correlation between political transparency and each of the four components of the Cukierman-Webb-Neyapti index, which pertain to (i) the appointment, dismissal and terms of office of the central bank governor; (ii) policy formulation and conflict resolution with the government; (iii) objectives of the central bank; and (iv) limitations on lending to the public sector.

The component of the Cukierman-Webb-Neyapti index relating to the central bank governor has a significant positive correlation with total, political, procedural and operational transparency. This suggests that central bank governors with long terms of office whose appointment and possible dismissal is protected from political influence, feel more secure to adopt transparency. In addition, the Cukierman-Webb-Neyapti sub-index for the central bank's objectives is significantly positively related to political and operational transparency. This indicates that central banks whose legal objectives are more focused on price stability are more likely to explain deviations in macroeconomic outcomes from their objectives.

Concerning de facto central bank independence, there is a mild negative correlation of -0.129 (with p-value 0.286) between the 1995-2004 turnover of central bank governors and the average level of the Eijffinger-Geraats transparency index from 1998 to 2004 for a sample of 70 central banks, with similar values for the five components of the index.

All in all, there is only a positive relation between transparency and central bank independence with respect to the governor and monetary policy objectives, ignoring the relation with political transparency that is due to direct overlap. Moreover, there appears to be no relation between central bank independence and policy and economic transparency, which are the components that have shown the largest increase during the last decade. This suggests that the rise in transparency is not simply a counterpart of greater central bank independence.

This raises the question what may be the reasons behind transparency improvements. Dincer and Eichengreen (2007) analyze the determinants of transparency using crosssection and panel-data regressions and find that the Eijffinger-Geraats transparency index is increasing in GDP per capita, openness and the flexibility of the de facto exchange rate regime, while the level of past inflation has no significant effect. In addition, there is a positive cross-section relation with governance measures, in particular voice and accountability, and government efficiency. Crowe and Meade (2008) run a cross-section regression for 40 countries (12 of which are in the euro zone) and also find that their 
Table 5: Transparency trend correlations

\begin{tabular}{lccrc} 
Correlation & \multicolumn{2}{c}{1998 inflation } & \multicolumn{2}{c}{ log GDP } \\
\hline Transparency capita \\
- Political & $\mathbf{0 . 3 5 6}$ & {$[0.000]$} & 0.139 & {$[0.185]$} \\
- Economic & $\mathbf{0 . 4 3 8}$ & {$[0.000]$} & 0.028 & {$[0.793]$} \\
- Procedural & -0.032 & {$[0.763]$} & $\mathbf{0 . 3 6 1}$ & {$[0.000]$} \\
- Policy & 0.199 & {$[0.059]$} & -0.005 & {$[0.963]$} \\
- Operational & 0.120 & {$[0.259]$} & 0.116 & {$[0.267]$} \\
Observations & $\mathbf{0 . 3 9 0}$ & {$[0.000]$} & -0.076 & {$[0.470]$} \\
\hline
\end{tabular}

Note: Pearson correlation coefficients with p-values in square brackets. Coefficients in bold are significant at 5\%. Sources: See data appendix.

transparency measure for 2003 is positively related to exchange rate flexibility and governance measures for regulatory quality and voice and accountability. Furthermore, they include the Cukierman-Webb-Neyapti index of central bank independence (which partly overlaps with their transparency measure) and (not surprisingly) find a strong positive relation, while GDP per capita has no significant effect.

To explore the macroeconomic context of the observed transparency trends, table 5 shows the correlation between the change in (components of) the Eijffinger-Geraats transparency index from 1998 to 2006 and two key macroeconomic variables, the level of inflation and log GDP per capita in 1998. The initial level of inflation is strongly positively correlated with the subsequent increase in the transparency index. The effect is highly significant, also for political and operational transparency. These correlation coefficients remain significant when a transformed level of inflation is used to reduce the sensitivity to outliers. ${ }^{12}$ Thus, it appears that higher inflation induces greater transparency, in particular about the monetary policy objectives and about unanticipated transmission shocks that cause inflation outcomes to deviate from the central bank's intentions. In addition, the level of GDP per capita is positively related to the transparency increase, especially for economic transparency which has a highly significant correlation. This suggests that more advanced countries have adopted greater transparency, in particular by releasing their macroeconometric model and forecasts. The latter impose considerable demands on the technical expertise of central bank staff, which may be challenging to meet for some developing countries.

Another issue is the level of inflation following the adoption of transparency. Table 6 shows that the levels of transparency in 2003 are negatively correlated with subsequent

\footnotetext{
${ }^{12}$ To be precise, the transformation is $\pi /(100+\pi)$, where $\pi$ is inflation in percent. The 1998 level of inflation in the sample ranges from $-1.3 \%$ (in Barbados) to $84.6 \%$ (in Turkey), with an average of $9.8 \%$.
} 
Table 6: Correlations between transparency and inflation

\begin{tabular}{lcccc} 
Correlation & \multicolumn{4}{c}{ Average inflation, 2004-2007 } \\
& Full sample & Excl. FX targeters \\
\hline Transparency in 2003 & $\mathbf{- 0 . 4 0 8}$ & {$[0.000]$} & $\mathbf{- 0 . 6 0 4}$ & {$[0.000]$} \\
- Political & $\mathbf{- 0 . 2 0 8}$ & {$[0.046]$} & $\mathbf{- 0 . 4 1 6}$ & {$[0.001]$} \\
- Economic & $\mathbf{- 0 . 4 3 6}$ & {$[0.000]$} & $\mathbf{- 0 . 6 1 0}$ & {$[0.000]$} \\
- Procedural & $\mathbf{- 0 . 3 3 4}$ & {$[0.001]$} & $\mathbf{- 0 . 4 6 6}$ & {$[0.000]$} \\
- Policy & $\mathbf{- 0 . 3 4 6}$ & {$[0.001]$} & $\mathbf{- 0 . 4 7 7}$ & {$[0.000]$} \\
- Operational & $\mathbf{- 0 . 2 6 1}$ & {$[0.012]$} & $\mathbf{- 0 . 4 5 4}$ & {$[0.000]$} \\
Observations & 92 & & 58 & \\
\hline
\end{tabular}

Note: Pearson correlation coefficients with p-values in square brackets. Coefficients in bold are significant at 5\%. Exchange rate (FX) targeters are identified based on de facto IMF classification as of 30 June 2003. Sources: See data appendix.

average inflation from 2004 to 2007. The correlations are all significant. These results are robust to the choice of the sample period for subsequent average inflation. ${ }^{13}$ However, the correlations become insignificant and sometimes even slightly positive when the average of inflation is taken over the preceding period from 1998 to 2002. In addition, it is interesting that the correlation coefficient is (robustly) largest for economic transparency, which may explain why this aspect of transparency has proved so popular among central banks.

When exchange rate targeters are excluded from the sample, the correlations between transparency and subsequent average inflation become notably stronger and all highly significant. This would be expected based on the theory discussed in section 2. Transparency exerts a disciplinary effect on discretionary monetary policymaking, which reduces the inflation bias and the sacrifice ratio. But this argument does not apply to exchange rate targeters, since their commitment to exchange rate stability constrains their monetary policy actions so transparency exerts little effect. Indeed, the correlation between the 2003 level of transparency and 2004-2007 average inflation for the group of 34 countries with exchange rate targeting is only -0.075 . For monetary targeting and inflation targeting the correlations are considerably stronger, -0.253 and -0.203 , respectively, though not statistically significant due to their small sample sizes. Countries with other monetary policy frameworks exhibit the strongest correlation, -0.563 with a p-value of 0.003 .

\footnotetext{
${ }^{13}$ In particular, they also hold for average inflation in the periods 2004-2006, 2005-2006 and 2005-2007. Note that the year 2003 is chosen for the transparency data because it is the first year for which the IMF classification of monetary policy frameworks is available.
} 
Figure 7: Relation between transparency and inflation.

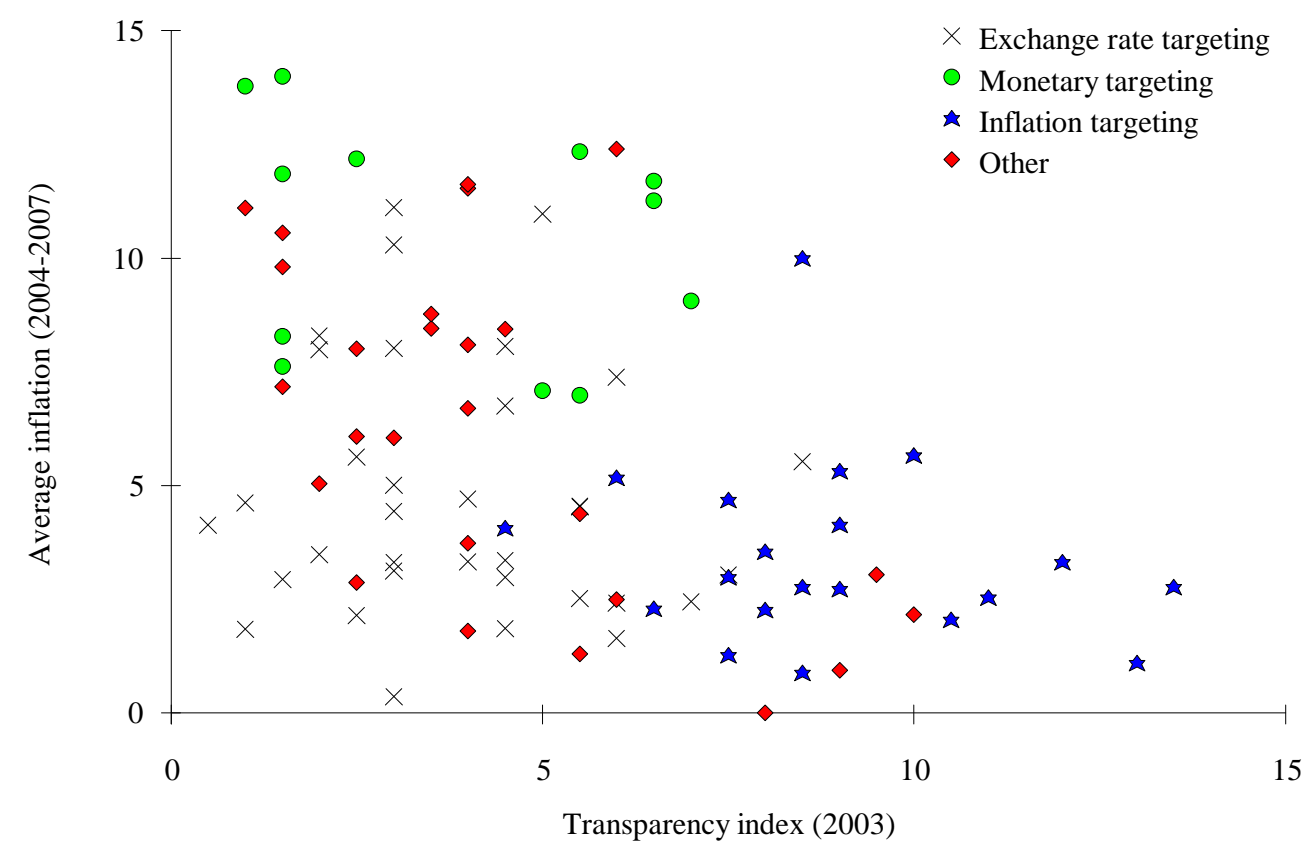

Note: Eijffinger-Geraats transparency index for 2003. Sample: 92 central banks. Sources: See data appendix.

The contribution of the different monetary policy frameworks to the negative relationship between transparency and inflation is illustrated in figure 7. Average inflation during the period 2004-2007 was quite low for the 92 countries in the sample, ranging from $0 \%$ (in Japan) to $14 \%$ (in Zambia), with a sample average of 5.7\%. Countries with exchange rate targeting tend to have low levels of transparency and average inflation. Their commitment to an exchange rate target allows them to secure low inflation with little transparency. Countries with monetary targeting also have low levels of transparency but typically higher average inflation. Inflation targeters, on the other hand, generally combine high levels of transparency with low average inflation. Finally, countries with other monetary policy frameworks vary considerably in their levels of transparency and average inflation, exhibiting a strong negative correlation.

There is also a strong association between the level of transparency and (log) GDP per capita in 2003, with a correlation of 0.556 (with p-value 0.000). A significant relation persists for each monetary policy framework, with a coefficient [and p-value] of 0.411 [0.014], 0.631 [0.037], 0.408 [0.074] and 0.699 [0.000] for exchange rate targeting, monetary targeting, inflation targeting, and others, respectively.

The contribution of the different monetary policy frameworks to the positive relationship between transparency and GDP per capita is illustrated in figure 8. It shows 
Figure 8: Relation between transparency and GDP per capita.

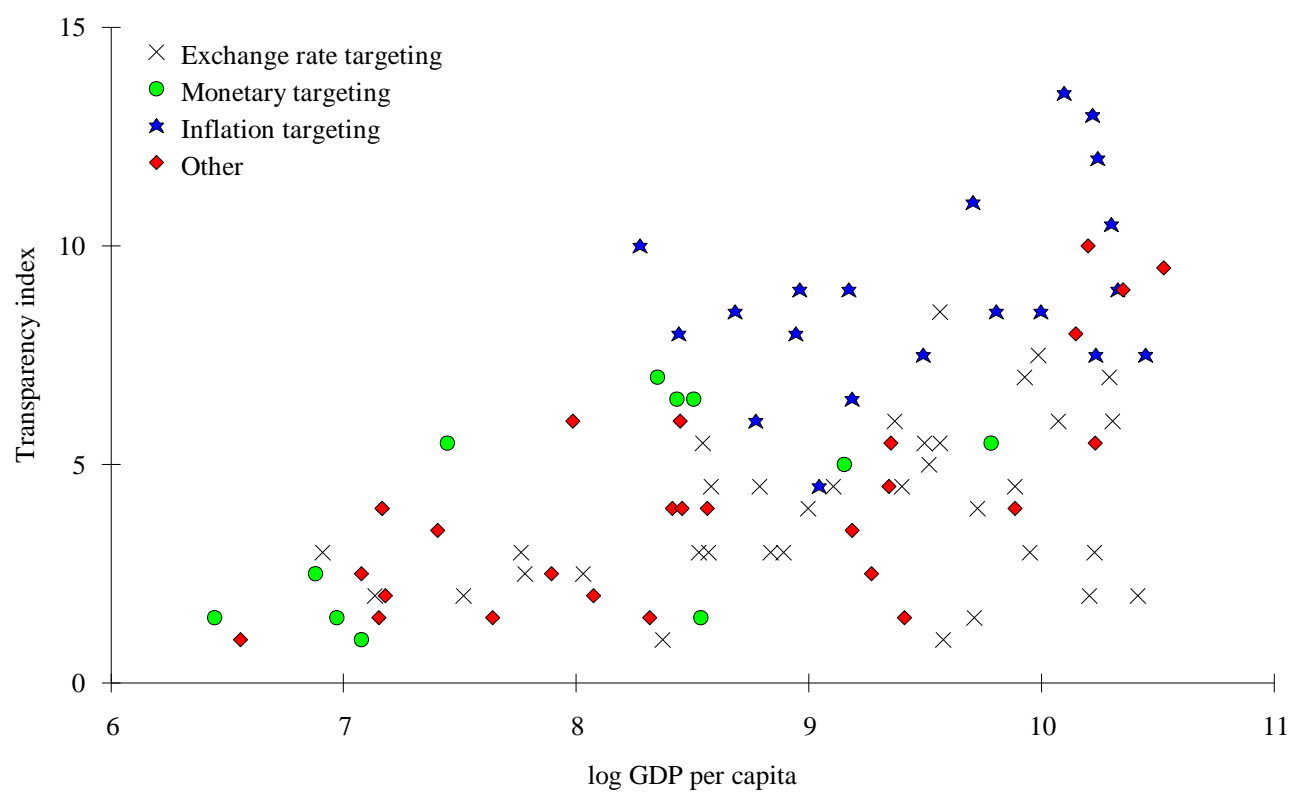

Note: Eijffinger-Geraats transparency index for 2003. Sample: 93 countries, 2003. Sources: See data appendix.

that countries with monetary targeting tend to have a low GDP per capita and low transparency, whereas inflation targeters generally enjoy higher levels of GDP per capita and transparency. Countries with exchange rate targeting or non-targeting frameworks show greater variation in both the level of economic development and monetary policy transparency.

All in all, these results provide some stylized facts. The long term transparency trend is positively related to the initial level of inflation and the level of economic development. Countries with higher monetary policy transparency tend to experience lower subsequent inflation. Inflation targeters tend to have low inflation and high GDP per capita, while the reverse holds for monetary targeters.

Of course, this descriptive exploration of the macroeconomic environment cannot establish cause and effect. However, there have been several econometric studies of the macroeconomic effects of transparency. Chortareas, Stasavage and Sterne (2002) use the Fry et al. (2000) survey and find that average inflation is significantly decreasing in the extent to which central banks publish forward-looking analysis and forecasts, controlling for institutional characteristics (such as central bank independence and political instability) and macroeconomic features (like GDP per capita and openness). But the negative relation between inflation and forecast transparency does not hold for countries with an exchange rate peg. These findings are consistent with the theory discussed in section 2 , 
which predicts that economic and operational transparency have a beneficial incentive effect that reduces the inflationary bias of discretionary monetary policy. Furthermore, Chortareas, Stasavage and Sterne (2003) find that greater transparency lowers the sacrifice ratio.

Ball and Sheridan (2003) argue that the greater reduction in inflation for inflation targeters simply reflects regression to the mean. It is true that after temporary price shocks, inflation tends to revert back to 'underlying' or 'core' inflation. However, high levels of core inflation generally do not magically vanish without the concerted efforts of central bankers. The argument of regression to the mean by Ball and Sheridan (2003) is difficult to reconcile with the fact that many countries have suffered from persistently high inflation.

Dincer and Eichengreen (2007) exploit their panel data set and find that transparency has a significant negative effect on the variability of inflation and output, controlling for macroeconomic features (including openness, financial depth and past inflation) and using instrumental variables (in particular, the rule of law) to take into account possible endogeneity of transparency. Crowe and Meade (2008) find a significantly positive relation between their transparency measure and the relative accuracy of private sector forecasts for inflation. van der Cruijsen and Demertzis (2007) find that greater transparency tends to make private sector inflation expectations less sensitive to past inflation outcomes. There is also evidence that transparency improves the predictability of monetary policy actions (e.g. Gerlach-Kristen 2004, Swanson 2006).

Overall, the empirical evidence so far indicates that monetary policy transparency largely has had beneficial macroeconomic effects.

\section{Transparency Challenges}

While there has been a pronounced increase in the transparency of monetary policy over the last decade, considerable challenges remain. This section briefly discusses three issues: the (sometimes misguided) focus of central banks on (short-run) predictability; the communication of policy deliberations and the role of press conferences; and the publication of the projected policy path.

Monetary policy transparency refers to the absence of asymmetric information about monetary policymaking. So, a transparent central bank is predictable. Some central banks seem to believe that the converse also holds - that a predictable central bank must be transparent. However, monetary policy actions could be predictable even without transparency. For instance, there could be a very stable macroeconomic environment so that the policy rate does not have to be adjusted. Or a central bank could clearly signal the next policy decision in advance, like the traffic-light system of code word communication of 
the European Central Bank (ECB), which is discussed by Geraats, Giavazzi and Wyplosz (2008). Thus, financial markets may manage to confidently predict the next policy move without really understanding monetary policymaking.

Although the predictability of monetary policy actions certainly has merits, it should not be considered an end in itself. In particular, it is important not to distort monetary policy actions to achieve predictability, but rather to use central bank communications to this effect. For instance, by delaying policy decisions to avoid market surprises it becomes harder for the public to understand the central bank's monetary policy reaction. As a result, a focus on short-term predictability could actually undermine monetary policy transparency, harm credibility and reduce predictability in the medium and long run.

To understand monetary policymaking it is invaluable to have the minutes of the monetary policy meetings, which is an area where secrecy still prevails. Minutes shed light on the arguments that were discussed and the policy options that were considered. In addition, the voting records would be very useful. ${ }^{14}$ In particular, the direction of dissenting votes provides information about the policy inclination, while the number of dissents indicates the likelihood of a policy move in that direction. Thus, the publication of voting records improves short-run predictability of policy decisions, as shown by GerlachKristen (2004). Furthermore, dissenting voices provide an indication of the ambiguity of the macroeconomic signals, which allows the public to better understand the monetary policy reaction. As a result, the publication of minutes and voting patterns enhances the medium term predictability of monetary policy.

Some central banks do not release minutes but hold a press conference after the monetary policy meeting (e.g. Norges Bank and the ECB). This could in principle be an adequate and even more timely substitute for minutes. Moreover, the question and answer session could identify transparency gaps. However, the value of press conferences is limited when the central banker's responses are reticent. In addition, the ability to appropriately field questions about delicate monetary policy issues requires considerable communication skills. So, it is preferable to remedy transparency gaps through controlled releases rather than risking slips of the tongue.

Last but not least, the frontier in monetary policy transparency - the publication of the projected interest rate path. Since the effect of a monetary policy decision depends on expected future decisions, the projected policy path is an integral part of the monetary policy stance. It provides an important tool for central banks to influence market expectations and thereby enhance the effectiveness of monetary policy. But the communication

\footnotetext{
${ }^{14}$ Some central banks claim to decide 'by consensus' (although they legally should decide by simple majority), but evidence from central banks that publish voting patterns shows that disagreements about monetary policy decisions are very common (Geraats et al. 2008), which suggests that consensus decisionmaking suppresses dissent or at least fails to communicate it.
} 
of the projected policy path poses an important challenge unlike other macroeconomic forecasts. Since the policy rate is directly controlled by the central bank, the projected path could be confused for a commitment. So, it is vital to convey the underlying uncertainty, which is most effectively done in a fan chart. In addition, it is helpful to publish the path for a short run (e.g. three-month) interest rate which is not the policy instrument of the central bank to prevent the interest rate path from being perceived as a commitment.

Although the publication of the projected interest rate path yields a beneficial information effect as it reduces uncertainty (Rudebusch and Williams 2006), there could be a detrimental incentive effect similar to Morris and Shin (2002). In particular, the projected interest rate path requires assumptions about how financial markets react to deviations from their expectations. Since central banks may not be very accurate gauging these financial market reactions, the projected interest rate path could be quite noisy so that its publication could induce greater economic volatility. In addition, the reliance of financial markets on the published path to coordinate their actions would reduce the informativeness of market signals (Morris and Shin 2005). Nevertheless, when market expectations differ significantly from the projected interest rate path, the central bank could greatly benefit from publishing it to facilitate the alignment of expectations and increase the effectiveness of monetary policy.

\section{Conclusions}

While a few decades ago central banks were often notorious for their secrecy, nowadays they tend to pride themselves on their degree of transparency. In fact, central bank communications have become an important tool for monetary policymaking. This paper establishes three stylized facts about monetary policy transparency around the world during the last decade.

First, there has been a remarkable rise in the disclosure of information pertinent to monetary policymaking. Although there has been greater openness in many respects, the most pronounced increase has been in the communication of policy decisions and the macroeconomic analysis on which they are based.

Second, there are significant differences in the degree of information disclosure across monetary policy frameworks. Central banks with inflation targeting have experienced the highest average level and increase in transparency, whereas monetary and exchange rate targeters have exhibited the lowest level and increase in information disclosure. Central banks without an explicit targeting framework have had intermediate levels and increases in transparency. Nevertheless, all monetary policy frameworks have seen a significant increase in information disclosure during the last decade.

Third, the increase in transparency has been significantly positively correlated with 
the initial level of inflation and the level of GDP per capita. Furthermore, there is a significantly negative correlation between monetary policy transparency and subsequent inflation.

So, it looks like central banks have used transparency to improve credibility and reduce inflation, which is in line with theoretical arguments. It is also consistent with econometric findings in the literature that monetary policy transparency makes inflation expectations less sensitive to past inflation outcomes, reduces average inflation and the sacrifice ratio, limits the variability of inflation and output, and also makes monetary policy more predictable. Thus, a central bank that invests in its communication tools could enhance the effectiveness of monetary policy.

Although the level of transparency has generally increased, the types of information central banks tend to disclose systematically depend on their monetary policy framework. In particular, exchange rate targeters have remained relatively opaque. This is likely because the lack of discretion reduces beneficial incentive effects of transparency. Monetary targeters have improved most in terms of transparency about unanticipated control errors and transmission disturbances, which are known to be important in this framework. Although inflation targeters have greatly increased transparency in all respects, their emphasis has been on the disclosure of anticipated macroeconomic disturbances, which is in line with the forward-looking nature of this framework. As a result, the differences in transparency reflect the characteristics of the monetary policy frameworks.

All in all, the paper shows a rich variety in disclosure practices over time and across monetary policy frameworks. Although central banks have adopted greater transparency in many respects, they remain opaque in some areas, in particular the disclosure of information about policy deliberations and policy inclinations. This is not surprising since there can be considerable communication challenges. But some central banks appear to have overcome them successfully, which may inspire others to follow suit. Thus, the trend in monetary policy transparency is likely to continue. 


\section{Data Appendix}

- Central bank independence: Cukierman et al. (1992)index of de jure central bank independence, compiled by Crowe and Meade (2008) for 99 central banks for 2003.

- GDP per capita: Real gross domestic product per capita in 2003 (PPP converted, in current prices, in USD). Source: Penn World Table, version 6.2 (Heston, Summers and Aten 2006); for the Euro area, ECB Statistics Pocket Book, June 2005.

- Inflation: Annual CPI inflation in percent. Source: IMF International Financial Statistics.

- Monetary policy framework: Exchange rate targeting, monetary targeting, inflation targeting or other based on de facto framework. Source: IMF Classification of Exchange Rate Arrangements and Monetary Policy Frameworks (http://www.imf.org/external/np/mfd/er/index.asp).

- Transparency: Eijffinger and Geraats (2006) index for central bank transparency, ranging from 0 to 15, compiled by Dincer and Eichengreen (2007) for 100 central banks from 1998 to 2006.

- Sample: Albania; Argentina; Armenia; [Aruba]; Australia; The Bahamas; Bahrain; Bangladesh; Barbados; Belarus; Belize; Bhutan; Brazil; Bulgaria; Canada; Chile; China (Mainland); Colombia; Croatia; Cyprus; Czech Republic; Denmark; [East Caribbean]; Egypt; El Salvador; Estonia; Ethiopia; Euro area; Fiji; Georgia; Ghana; Guatemala; [Guyana]; [Hong Kong]; Hungary; Iceland; India; Indonesia; [Iraq]; Israel; Jamaica; Japan; Jordan; Kazakhstan; Kenya; Korea; Kuwait; [Kyrgyz Republic]; Latvia; Lesotho; [Libya]; Lithuania; Malawi; Malaysia; Malta; Mauritius; Mexico; Moldova; Mongolia; [Namibia]; New Zealand; Nigeria; Norway; [Oman]; Pakistan; Papua New Guinea; Peru; Philippines; Poland; Qatar; Romania; Russia; Rwanda; Saudi Arabia; Sierra Leone; Singapore; Slovak Republic; Slovenia; Solomon Islands; South Africa; Sri Lanka; Sudan; Sweden; Switzerland; [Tajikistan]; Thailand; Trinidad And Tobago; Tunisia; Turkey; Uganda; Ukraine; [United Arab Emirates]; United Kingdom; United States; Uruguay; Vanuatu; Yemen; Zambia.

This is the Dincer and Eichengreen (2007) sample excluding Bermuda and Cuba, which are not included in the IMF classification of monetary policy frameworks. The 11 countries in square brackets are not in all the samples due to limited availability of data. 


\section{References}

Ball, L. and Sheridan, N. (2003), 'Does inflation targeting matter?', NBER Working Paper 9577.

Blinder, A. S. (2000), 'Central-bank credibility: Why do we care? how do we build it?', American Economic Review 90(5), 1421-1431.

Blinder, A. S., Ehrmann, M., Fratzscher, M., Haan, J. D. and Jansen, D.-J. (2008), 'Central bank communication and monetary policy: A survey of theory and evidence', NBER Working Paper 13932.

Chortareas, G., Stasavage, D. and Sterne, G. (2002), 'Does it pay to be transparent? International evidence from central bank forecasts', Federal Reserve Bank of St. Louis Review 84(4), 99-117.

Chortareas, G., Stasavage, D. and Sterne, G. (2003), 'Does monetary policy transparency reduce disinflation costs?', The Manchester School 71(5), 521-540.

Crowe, C. and Meade, E. E. (2008), 'Central bank independence and transparency: Evolution and effectiveness', IMF Working Paper 08/119.

Cukierman, A. (2001), Accountability, credibility, transparency and stabilization policy in the eurosystem, in C. Wyplosz, ed., 'The Impact of EMU on Europe and the Developing Countries', Oxford University Press, chapter 3, pp. 40-75.

Cukierman, A. and Meltzer, A. H. (1986), 'A theory of ambiguity, credibility, and inflation under discretion and asymmetric information', Econometrica 54(5), 1099-1128.

Cukierman, A., Webb, S. B. and Neyapti, B. (1992), 'Measuring the independence of central banks and its effect on policy outcomes', World Bank Economic Review 4(3), 353-398.

Dincer, N. N. and Eichengreen, B. (2007), 'Central bank transparency: Where, why, and with what effects?', NBER Working Paper 13003.

Eijffinger, S. C. and Geraats, P. M. (2006), 'How transparent are central banks?', European Journal of Political Economy 22(1), 1-21.

Faust, J. and Svensson, L. E. (2001), 'Transparency and credibility: Monetary policy with unobservable goals', International Economic Review 42(2), 369-397. 
Fry, M., Julius, D., Mahadeva, L., Roger, S. and Sterne, G. (2000), Key issues in the choice of monetary policy framework, in L. Mahadeva and G. Sterne, eds, 'Monetary Policy Frameworks in a Global Context', Routledge, London, pp. 1-216.

Geraats, P., Giavazzi, F. and Wyplosz, C. (2008), 'Transparency and governance', Monitoring the European Central Bank 6, Centre for Economic Policy Research.

Geraats, P. M. (2000), 'Why adopt transparency? The publication of central bank forecasts', CEPR Discussion Paper 2582.

Geraats, P. M. (2001), 'Precommitment, transparency and monetary policy', Bundesbank Discussion Paper 12/01.

Geraats, P. M. (2002), 'Central bank transparency', Economic Journal 112(483), F532F565.

Geraats, P. M. (2005), 'Transparency and reputation: The publication of central bank forecasts', Topics in Macroeconomics 5(1.1), 1-26.

Geraats, P. M. (2006), 'Transparency of monetary policy: Theory and practice', CESifo Economic Studies 52(1), 111-152.

Geraats, P. M. (2007), 'The mystique of central bank speak', International Journal of Central Banking 3(1), 37-80.

Gerlach-Kristen, P. (2004), 'Is the MPC's voting record informative about future UK monetary policy?', Scandinavian Journal of Economics 106(2), 299-313.

Heston, A., Summers, R. and Aten, B. (2006), 'Penn world table version 6.2', Center for International Comparisons of Production, Income and Prices at the University of Pennsylvania.

Meade, E. E. and Stasavage, D. (2004), 'Publicity of debate and the incentive to dissent: Evidence from the US federal reserve', CEP Discussion Paper 0608.

Morris, S. and Shin, H. S. (2002), 'Social value of public information', American Economic Review 92(5), 1521-1534.

Morris, S. and Shin, H. S. (2005), 'Central bank transparency and the signal value of prices', Brookings Papers on Economic Activity 2005(2).

Rudebusch, G. D. and Williams, J. C. (2006), 'Revealing the secrets of the temple: The value of publishing interest rate projections', NBER Working Paper 12638. 
Svensson, L. E. (1997), 'Inflation forecast targeting: Implementing and monitoring inflation targets', European Economic Review 41(6), 1111-1146.

Swanson, E. T. (2006), 'Have increases in federal reserve transparency improved private sector interest rate forecasts?', Journal of Money, Credit, and Banking 38(3), 791819.

Tong, H. (2005), 'Disclosure standards and market efficiency: Evidence from analysts' forecasts', Paper presented at the AFA Annual Meeting in Philadelphia, January 2005. http://ssrn.com/abstract=641842.

van der Cruijsen, C. and Demertzis, M. (2007), 'The impact of central bank transparency on inflation expectations', European Journal of Political Economy 23(1), 51-66.

Walsh, C. E. (2007), 'Optimal economic transparency', International Journal of Central Banking 3(1), 5-36. 


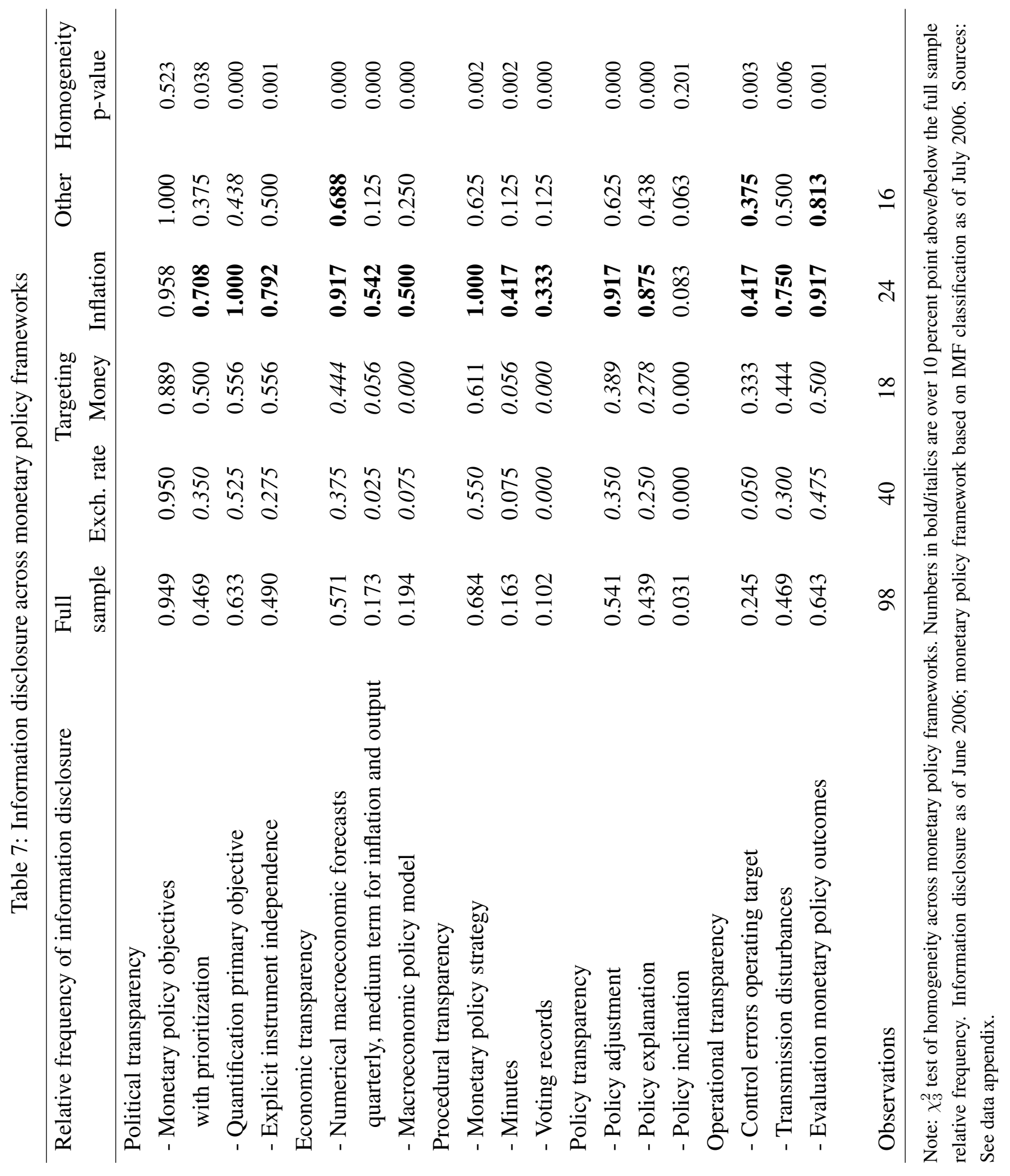




\section{CESifo Working Paper Series}

for full list see www.cesifo-group.org/wp

(address: Poschingerstr. 5, 81679 Munich, Germany, office@cesifo.de)

2521 Geir B. Asheim and Tapan Mitra, Sustainability and Discounted Utilitarianism in Models of Economic Growth, January 2009

2522 Etienne Farvaque and Gaël Lagadec, Electoral Control when Policies are for Sale, January 2009

2523 Nicholas Barr and Peter Diamond, Reforming Pensions, January 2009

2524 Eric A. Hanushek and Ludger Woessmann, Do Better Schools Lead to More Growth? Cognitive Skills, Economic Outcomes, and Causation, January 2009

2525 Richard Arnott and Eren Inci, The Stability of Downtown Parking and Traffic Congestion, January 2009

2526 John Whalley, Jun Yu and Shunming Zhang, Trade Retaliation in a Monetary-Trade Model, January 2009

2527 Mathias Hoffmann and Thomas Nitschka, Securitization of Mortgage Debt, Asset Prices and International Risk Sharing, January 2009

2528 Steven Brakman and Harry Garretsen, Trade and Geography: Paul Krugman and the 2008 Nobel Prize in Economics, January 2009

2529 Bas Jacobs, Dirk Schindler and Hongyan Yang, Optimal Taxation of Risky Human Capital, January 2009

2530 Annette Alstadsæter and Erik Fjærli, Neutral Taxation of Shareholder Income? Corporate Responses to an Announced Dividend Tax, January 2009

2531 Bruno S. Frey and Susanne Neckermann, Academics Appreciate Awards - A New Aspect of Incentives in Research, January 2009

2532 Nannette Lindenberg and Frank Westermann, Common Trends and Common Cycles among Interest Rates of the G7-Countries, January 2009

2533 Erkki Koskela and Jan König, The Role of Profit Sharing in a Dual Labour Market with Flexible Outsourcing, January 2009

2534 Tomasz Michalak, Jacob Engwerda and Joseph Plasmans, Strategic Interactions between Fiscal and Monetary Authorities in a Multi-Country New-Keynesian Model of a Monetary Union, January 2009

2535 Michael Overesch and Johannes Rincke, What Drives Corporate Tax Rates Down? A Reassessment of Globalization, Tax Competition, and Dynamic Adjustment to Shocks, February 2009 
2536 Xenia Matschke and Anja Schöttner, Antidumping as Strategic Trade Policy Under Asymmetric Information, February 2009

2537 John Whalley, Weimin Zhou and Xiaopeng An, Chinese Experience with Global 3G Standard-Setting, February 2009

2538 Claus Thustrup Kreiner and Nicolaj Verdelin, Optimal Provision of Public Goods: A Synthesis, February 2009

2539 Jerome L. Stein, Application of Stochastic Optimal Control to Financial Market Debt Crises, February 2009

2540 Lars P. Feld and Jost H. Heckemeyer, FDI and Taxation: A Meta-Study, February 2009

2541 Philipp C. Bauer and Regina T. Riphahn, Age at School Entry and Intergenerational Educational Mobility, February 2009

2542 Thomas Eichner and Rüdiger Pethig, Carbon Leakage, the Green Paradox and Perfect Future Markets, February 2009

2543 M. Hashem Pesaran, Andreas Pick and Allan Timmermann, Variable Selection and Inference for Multi-period Forecasting Problems, February 2009

2544 Mathias Hoffmann and Iryna Shcherbakova, Consumption Risk Sharing over the Business Cycle: the Role of Small Firms' Access to Credit Markets, February 2009

2545 John Beirne, Guglielmo Maria Caporale, Marianne Schulze-Ghattas and Nicola Spagnolo, Volatility Spillovers and Contagion from Mature to Emerging Stock Markets, February 2009

2546 Ali Bayar and Bram Smeets, Economic and Political Determinants of Budget Deficits in the European Union: A Dynamic Random Coefficient Approach, February 2009

2547 Jan K. Brueckner and Anming Zhang, Airline Emission Charges: Effects on Airfares, Service Quality, and Aircraft Design, February 2009

2548 Dolores Messer and Stefan C. Wolter, Money Matters - Evidence from a Large-Scale Randomized Field Experiment with Vouchers for Adult Training, February 2009

2549 Johannes Rincke and Christian Traxler, Deterrence through Word of Mouth, February 2009

2550 Gabriella Legrenzi, Asymmetric and Non-Linear Adjustments in Local Fiscal Policy, February 2009

2551 Bruno S. Frey, David A. Savage and Benno Torgler, Surviving the Titanic Disaster: Economic, Natural and Social Determinants, February 2009

2552 Per Engström, Patrik Hesselius and Bertil Holmlund, Vacancy Referrals, Job Search, and the Duration of Unemployment: A Randomized Experiment, February 2009 
2553 Giorgio Bellettini, Carlotta Berti Ceroni and Giovanni Prarolo, Political Persistence, Connections and Economic Growth, February 2009

2554 Steinar Holden and Fredrik Wulfsberg, Wage Rigidity, Institutions, and Inflation, February 2009

2555 Alexander Haupt and Tim Krieger, The Role of Mobility in Tax and Subsidy Competition, February 2009

2556 Harald Badinger and Peter Egger, Estimation of Higher-Order Spatial Autoregressive Panel Data Error Component Models, February 2009

2557 Christian Keuschnigg, Corporate Taxation and the Welfare State, February 2009

2558 Marcel Gérard, Hubert Jayet and Sonia Paty, Tax Interactions among Belgian Municipalities: Does Language Matter?, February 2009

2559 António Afonso and Christophe Rault, Budgetary and External Imbalances Relationship: A Panel Data Diagnostic, February 2009

2560 Stefan Krasa and Mattias Polborn, Political Competition between Differentiated Candidates, February 2009

2561 Carsten Hefeker, Taxation, Corruption and the Exchange Rate Regime, February 2009

2562 Jiahua Che and Gerald Willmann, The Economics of a Multilateral Investment Agreement, February 2009

2563 Scott Alan Carson, Demographic, Residential, and Socioeconomic Effects on the Distribution of $19^{\text {th }}$ Century US White Statures, February 2009

2564 Philipp Harms, Oliver Lorz and Dieter Urban, Offshoring along the Production Chain, February 2009

2565 Patricia Apps, Ngo Van Long and Ray Rees, Optimal Piecewise Linear Income Taxation, February 2009

2566 John Whalley and Shunming Zhang, On the Arbitrariness of Consumption, February 2009

2567 Marie-Louise Leroux, Endogenous Differential Mortality, Non-Contractible Effort and Non Linear Taxation, March 2009

2568 Joanna Bęza-Bojanowska and Ronald MacDonald, The Behavioural Zloty/Euro Equilibrium Exchange Rate, March 2009

2569 Bart Cockx and Matteo Picchio, Are Short-Lived Jobs Stepping Stones to Long-Lasting Jobs?, March 2009 
2570 David Card, Jochen Kluve and Andrea Weber, Active Labor Market Policy Evaluations: A Meta-analysis, March 2009

2571 Frederick van der Ploeg and Anthony J. Venables, Harnessing Windfall Revenues: Optimal Policies for Resource-Rich Developing Economies, March 2009

2572 Ondřej Schneider, Reforming Pensions in Europe: Economic Fundamentals and Political Factors, March 2009

2573 Jo Thori Lind, Karl Ove Moene and Fredrik Willumsen, Opium for the Masses? Conflict-Induced Narcotics Production in Afghanistan, March 2009

2574 Silvia Marchesi, Laura Sabani and Axel Dreher, Agency and Communication in IMF Conditional Lending: Theory and Empirical Evidence, March 2009

2575 Carlo Altavilla and Matteo Ciccarelli, The Effects of Monetary Policy on Unemployment Dynamics under Model Uncertainty - Evidence from the US and the Euro Area, March 2009

2576 Falko Fecht, Kjell G. Nyborg and Jörg Rocholl, The Price of Liquidity: Bank Characteristics and Market Conditions, March 2009

2577 Giorgio Bellettini and Filippo Taddei, Real Estate Prices and the Importance of Bequest Taxation, March 2009

2578 Annette Bergemann and Regina T. Riphahn, Female Labor Supply and Parental Leave Benefits - The Causal Effect of Paying Higher Transfers for a Shorter Period of Time, March 2009

2579 Thomas Eichner and Rüdiger Pethig, EU-Type Carbon Emissions Trade and the Distributional Impact of Overlapping Emissions Taxes, March 2009

2580 Antonios Antypas, Guglielmo Maria Caporale, Nikolaos Kourogenis and Nikitas Pittis, Selectivity, Market Timing and the Morningstar Star-Rating System, March 2009

2581 António Afonso and Christophe Rault, Bootstrap Panel Granger-Causality between Government Budget and External Deficits for the EU, March 2009

2582 Bernd Süssmuth, Malte Heyne and Wolfgang Maennig, Induced Civic Pride and Integration, March 2009

2583 Martin Peitz and Markus Reisinger, Indirect Taxation in Vertical Oligopoly, March 2009

2584 Petra M. Geraats, Trends in Monetary Policy Transparency, March 2009 